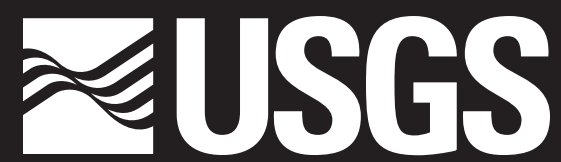

science for a changing world

Prepared in cooperation with the

Massachusetts Department of Environmental Protection

\title{
Ground-Water Contributions to Reservoir Storage and the Effect on Estimates of Firm Yield for Reservoirs in Massachusetts
}
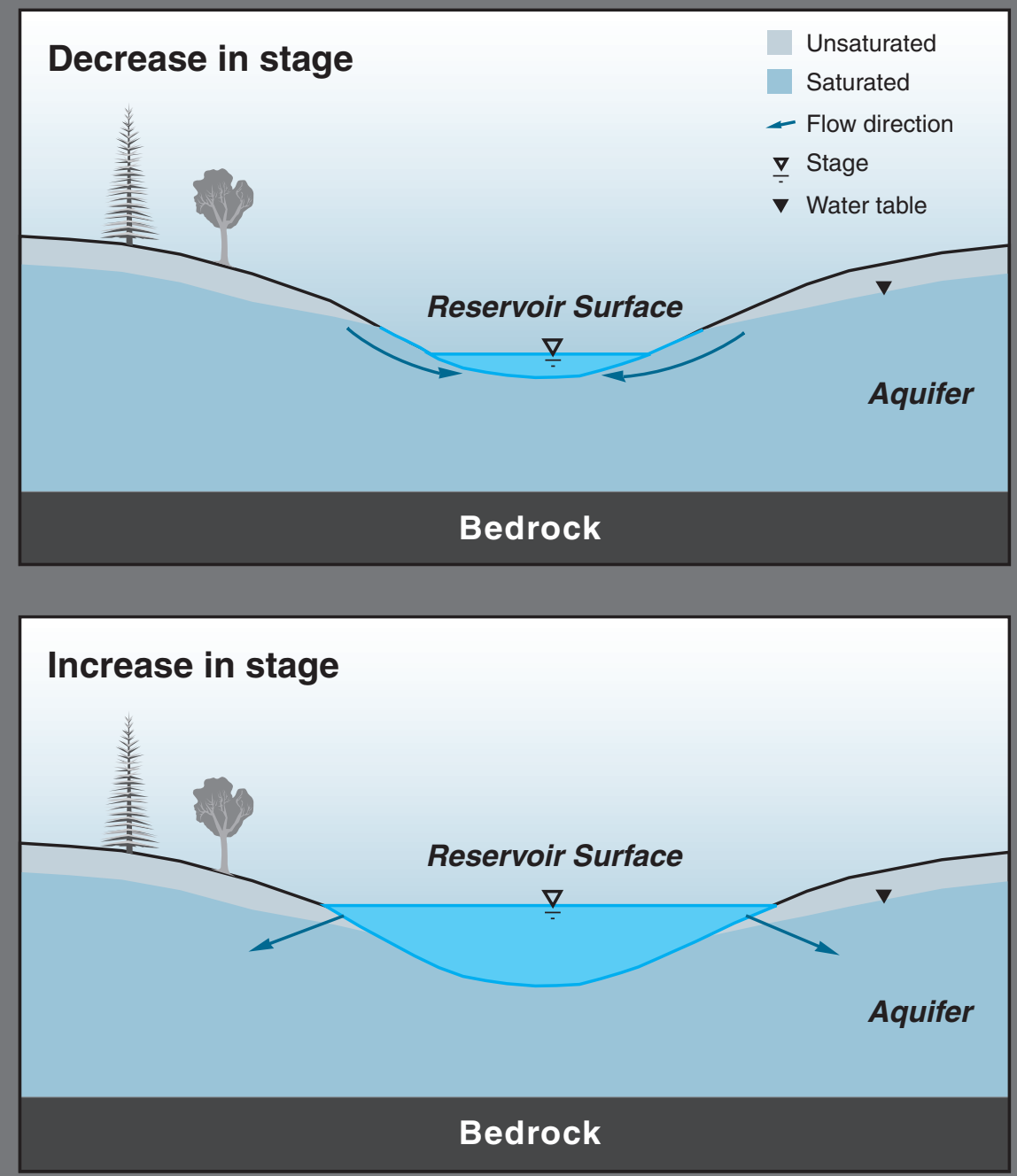

Scientific Investigations Report 2006-5045

U.S. Department of the Interior

U.S. Geological Survey 
Cover: Diagram showing the response of the aquifer to a decrease and an increase in reservoir stage, respectively. 


\section{Ground-Water Contributions to Reservoir Storage and the Effect on Estimates of Firm Yield for Reservoirs in Massachusetts}

By Stacey A. Archfield and Carl S. Carlson

Prepared in cooperation with the Massachusetts Department of Environmental Protection

Scientific Investigations Report 2006-5045 


\section{U.S. Department of the Interior \\ Gale A. Norton, Secretary \\ U.S. Geological Survey \\ P. Patrick Leahy, Acting Director}

\section{U.S. Geological Survey, Reston, Virginia: 2006}

For product and ordering information:

World Wide Web: http://www.usgs.gov/pubprod

Telephone: 1-888-ASK-USGS

For more information on the USGS--the Federal source for science about the Earth, its natural and living resources, natural hazards, and the environment:

World Wide Web: http://www.usgs.gov

Telephone: 1-888-ASK-USGS

Any use of trade, product, or firm names is for descriptive purposes only and does not imply endorsement by the U.S. Government.

Although this report is in the public domain, permission must be secured from the individual copyright owners to reproduce any copyrighted materials contained within this report.

Suggested citation:

Archfield, S.A., and Carlson, C.S., 2006, Ground-water contributions to reservoir storage and the effect on estimates of firm yield for reservoirs in Massachusetts: U.S. Geological Survey Scientific Investigations Report $2006-5045,27 p$ 


\section{Contents}

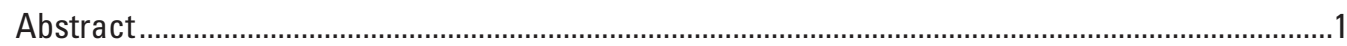

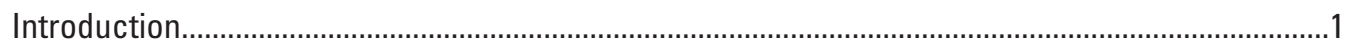

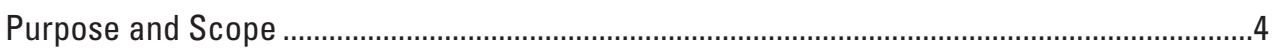

The Existing Firm-Yield-Estimator Model for Reservoirs in Massachusetts..............................4

Determination of Ground-Water Contributions to Reservoir Storage...............................................5

Numerical-Model Simulations of Idealized Reservoir-Aquifer Geometries .............................8

Analytical Simulations of Idealized Reservoir-Aquifer Geometries .........................................8

Effect of Reservoir Shape on the Flow Rate between the Reservoir and Aquifer....................8

Application of the Ground-Water-Flow Equations to the Firm-Yield-Estimator Model ..................10

Modifications to the Ground-Water-Flow Equations ...............................................................11

Numerical-Model Simulations of Ground-Water-Flow Rates and Reservoir Water Levels. . .14

Modified Firm-Yield-Estimator Model Simulations of Ground-Water-Flow Rates and Reservoir Water Levels .......................................................................................14

Comparison of Simulated Ground-Water-Flow Rates and Reservoir Water Levels.......14

Iterative Loop to Calculate the Change in Reservoir Stage......................................................17

Effect of Uncertainty in the Input Variables to the Ground-Water-Flow Equations........................20

Sensitivity of Firm Yield to the Reservoir Stage-Storage Relation...........................................20

Sensitivity of Firm Yield to Other Reservoir and Aquifer Input Variables ................................21

Potential Effect of Ground-Water Contributions on Firm Yields for Reservoirs

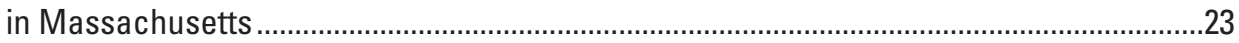

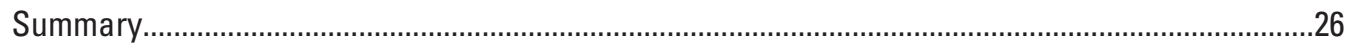

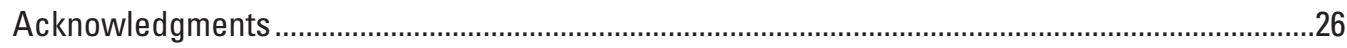

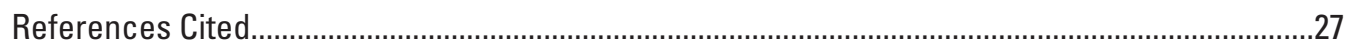




\section{Figures}

1-3. Diagrams showing:

1. Possible sources and losses of water for a hypothetical drinking-water reservoir

2. $A$, Reservoir water level at equilibrium with the water table in the surrounding aquifer; $B$, response of the water table to a decrease in the water level of the reservoir relative to the water table; or $C$, to an increase in the water level of the reservoir relative to the water table

3. $A$, Surface-water-body shapes; $B$, with underlying model grid (shown with surface-water-body shape 10 ) for reservoir-aquifer systems; and $C$, reservoirstage fluctuations used to evaluate the effects of reservoir-aquifer geometry on the analytical solution to the ground-water flow equation derived by Rorabaugh (1964)

4. Graphs showing differences between the numerically and analytically simulated ground-water-flow rates, and timing of the flows for selected reservoir-aquifer geometries shown in figure 3

5. Flow chart of the modified firm-yield-estimator model

6. Maps showing locations of four reservoir-aquifer systems in Massachusetts: $A$, Fitchburg Reservoir; $B$, Morse Reservoir; $C$, Bearhole Reservoir; and $D$, Millham Reservoir ......

7. Diagram of model grids used in the numerical simulations of four idealized reservoiraquifer systems patterned after the four reservoir-aquifer systems shown in figure 6 . Reservoir $A$ is patterned after Fitchburg Reservoir (fig. 6A); Reservoir $B$ is patterned after Morse Reservoir (fig. 6B); Reservoir $C$ is patterned after Bearhole Reservoir (fig. $6 C$ ); Reservoir $D$ is patterned after Millham Reservoir (fig. 6D)

8-10. Graphs showing:

8. $A$, Comparison of simulated average ground-water flow rates; and $B$, reservoir water-level elevations for four idealized reservoir-aquifer systems during a 2-year period of average climate and streamflow conditions (April 1975 through March 1977)....

9. Sensitivity of firm yield to the closure criterion used in the iterative loop of the firm-yield simulations for four idealized reservoir-aquifer systems.

10. Shape of the stage-storage relation for two drinking-water reservoirs: $A$, Bearhole Reservoir; and $B$, Fitchburg Reservoir.

11. Sensitivity of firm yield to reservoir and aquifer characteristics for four idealized reservoir-aquifer systems

12. Map showing locations of nine reservoirs that have shorelines in contact with sand and gravel aquifers.

\section{Tables}

1. Reservoir and aquifer characteristics for four idealized reservoir-aquifer systems......16

2. Estimated reservoir and aquifer characteristics for nine reservoirs in Massachusetts whose reservoir shorelines are in contact with a sand and gravel aquifer. .25

3. Potential effect of ground-water contributions to reservoir storage on firm yield for nine reservoirs in Massachusetts. 


\section{Conversion Factors, Horizontal Datum, and Abbreviations}

\begin{tabular}{|c|c|c|}
\hline Multiply & By & To obtain \\
\hline \multicolumn{3}{|c|}{ Length } \\
\hline inch (in.) & 2.54 & centimeter $(\mathrm{cm})$ \\
\hline foot $(\mathrm{ft})$ & 0.3048 & meter $(\mathrm{m})$ \\
\hline mile (mi) & 1.609 & kilometer (km) \\
\hline \multicolumn{3}{|c|}{ Area } \\
\hline square mile $\left(\mathrm{mi}^{2}\right)$ & 2.590 & square kilometer $\left(\mathrm{km}^{2}\right)$ \\
\hline \multicolumn{3}{|c|}{ Volume } \\
\hline gallon (gal) & 3.785 & liter (L) \\
\hline million gallons (Mgal) & 3,785 & cubic meter $\left(\mathrm{m}^{3}\right)$ \\
\hline cubic foot $\left(\mathrm{ft}^{3}\right)$ & 0.02832 & cubic meter $\left(\mathrm{m}^{3}\right)$ \\
\hline cubic mile $\left(\mathrm{mi}^{3}\right)$ & 4.168 & cubic kilometer $\left(\mathrm{km}^{3}\right)$ \\
\hline \multicolumn{3}{|c|}{ Flow rate } \\
\hline foot per day $(\mathrm{ft} / \mathrm{d})$ & 0.3048 & meter per day $(\mathrm{m} / \mathrm{d})$ \\
\hline gallon per day $(\mathrm{gal} / \mathrm{d})$ & 0.003785 & cubic meter per day $\left(\mathrm{m}^{3} / \mathrm{d}\right)$ \\
\hline million gallons per day (Mgal/d) & 0.04381 & cubic meter per second $\left(\mathrm{m}^{3} / \mathrm{s}\right)$ \\
\hline \multicolumn{3}{|c|}{ Transmissivity* } \\
\hline foot squared per day $\left(\mathrm{ft}^{2} / \mathrm{d}\right)$ & 0.09290 & meter squared per day $\left(\mathrm{m}^{2} / \mathrm{d}\right)$ \\
\hline
\end{tabular}

Horizontal coordinate information is referenced to the North American Datum of 1983 (NAD 83).

*Transmissivity: The standard unit for transmissivity is cubic foot per day per square foot times foot of aquifer thickness $\left[\left(\mathrm{ft}^{3} / \mathrm{d}\right) / \mathrm{ft}^{2}\right] \mathrm{ft}$. In this report, the mathematically reduced form, foot squared per day $\left(\mathrm{ft}^{2} / \mathrm{d}\right)$, is used for convenience.

\section{ABBREVIATIONS}

CHD Constant-Head Boundary

CN runoff-curve number

FYE Firm-Yield-Estimator

GIS Geographic Information System

MassDEP Massachusetts Department of Environmental Protection

QPPO streamflow-probability-probability-streamflow 



\title{
Ground-Water Contributions to Reservoir Storage and the Effect on Estimates of Firm Yield for Reservoirs in Massachusetts
}

\author{
By Stacey A. Archfield and Carl S. Carlson
}

\section{Abstract}

Potential ground-water contributions to reservoir storage were determined for nine reservoirs in Massachusetts that had shorelines in contact with sand and gravel aquifers. The effect of ground water on firm yield was not only substantial, but furthermore, the firm yield of a reservoir in contact with a sand and gravel aquifer was always greater when the ground-water contribution was included in the water balance. Increases in firm yield ranged from 2 to 113 percent, with a median increase in firm yield of 10 percent. Additionally, the increase in firm yield in two reservoirs was greater than 85 percent.

This study identified a set of equations that are based on an analytical solution to the ground-water-flow equation for the case of one-dimensional flow in a finite-width aquifer bounded by a linear surface-water feature such as a stream. These equations, which require only five input variables, were incorporated into an existing firm-yield-estimator (FYE) model, and the potential effect of ground water on firm yield was evaluated. To apply the FYE model to a reservoir in Massachusetts, the model requires that the drainage area to the reservoir be clearly defined and that some surface water flows into the reservoir. For surface-water-body shapes having a more realistic representation of a reservoir shoreline than a stream, a comparison of ground-water-flow rates simulated by the ground-water equations with flow rates simulated by a two-dimensional, finite-difference ground-water-flow model indicate that the agreement between the simulated flow rates is within \pm 10 percent when the ratio of the distance from the reservoir shoreline to the aquifer boundary to the length of shoreline in contact with the aquifer is between values of 0.5 and 3.5.

Idealized reservoir-aquifer systems were assumed to verify that the ground-water-flow equations were implemented correctly into the existing FYE model; however, the modified FYE model has not been validated through a comparison of simulated and observed data. A comparison of simulated and observed reservoir water levels would further define limitations to the applicability of the ground-water-flow equations to reservoirs in Massachusetts whose shorelines are in contact with a sand and gravel aquifer.

\section{Introduction}

The amount of water that is available for withdrawal from a drinking-water supply reservoir depends on the water balance of the reservoir. Reservoirs accumulate water from surface-water inflows and from precipitation on the reservoir surface; available storage is reduced by evaporation, releases to meet instream-flow requirements, and drinking-water withdrawals (fig. 1). Many of the terms in the water balance of a reservoir are derived from natural processes that cannot be altered. Consequently, to prevent reservoir failure, a withdrawal rate is chosen that maximizes the amount of water available for supply, but only allows for the complete depletion of available storage during one time interval over the period of simulation. The withdrawal rate that accomplishes this objective is termed the firm yield of the reservoir. Demands on a reservoir that are equal to or less than the firm yield ensure that the reservoir will always meet these demands, assuming the reservoir is affected by climatic and hydrologic conditions similar to those used in the evaluation. As demands for drinking-water supplies increase and available water is further reduced, calculation of the firm yield provides an upper boundary that can be used to evaluate the capacity of a reservoir to meet additional demands in excess of current withdrawals. Alternatively, the firm yield can be compared to current reservoir withdrawals to determine if these withdrawals could be sustained through a drought.

Water in available storage may be supplemented or reduced if a reservoir is in contact with an aquifer, due to the inflow of water from the aquifer to the reservoir or the outflow of water from the reservoir to the aquifer; however, because many reservoirs receive most of their water from a surfacewater source, the ground-water term in the water balance is assumed to be negligible and is ignored in the calculation of the firm yield. For a reservoir whose shoreline is in contact with an aquifer, as is the case for approximately one-quarter of the more than 70 drinking-water supply reservoirs in Massachusetts, the effect of ground-water contributions on firm yield is unknown because available models that are used to estimate firm yield were constructed without consideration for the ground-water contribution to reservoir storage. 


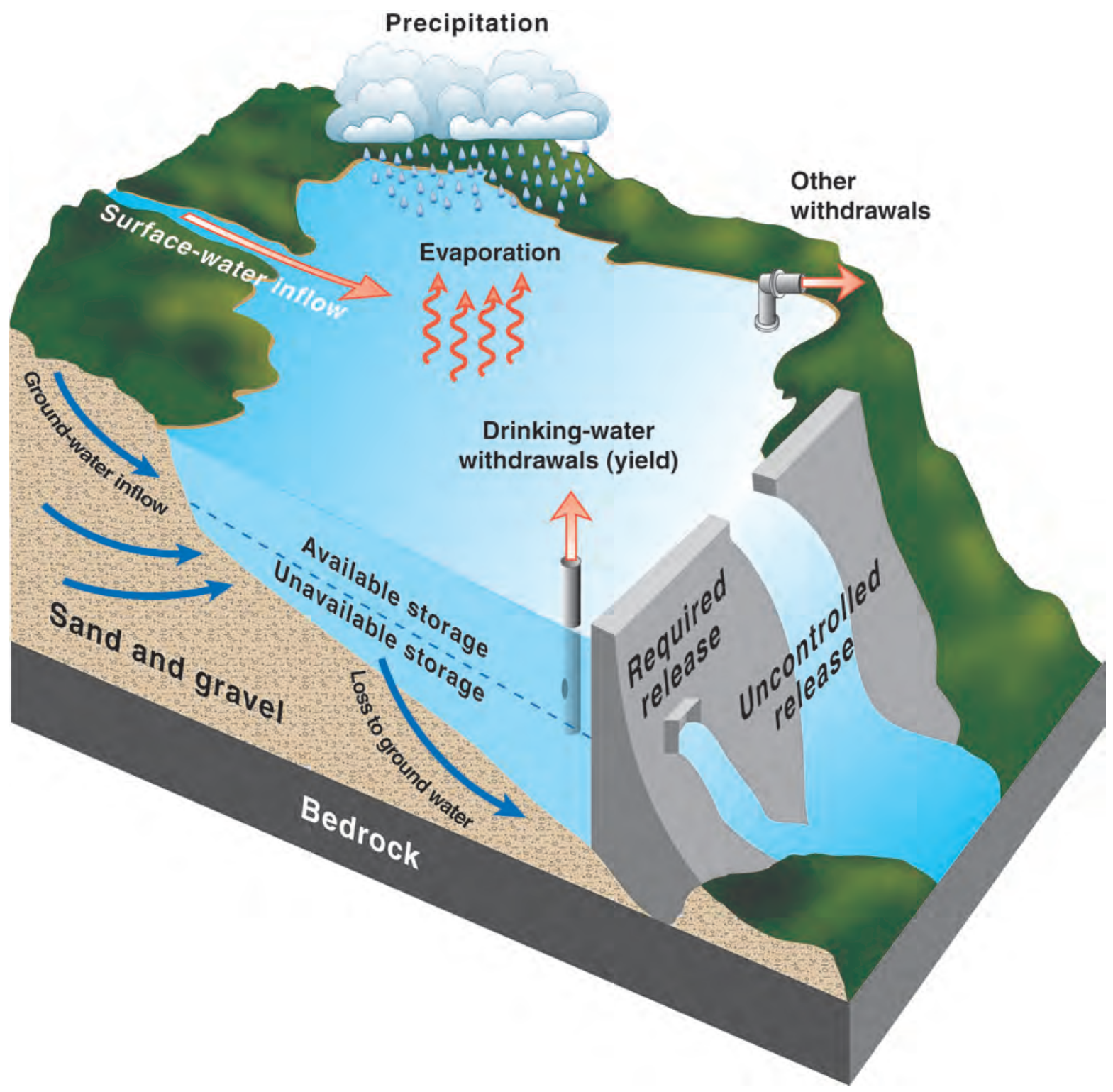

Figure 1. Possible sources and losses of water for a hypothetical drinking-water reservoir.

The reservoir storage and corresponding stage will increase or decrease due to changes in the reservoir-water balance. Therefore, if a reservoir is in hydrologic connection with an aquifer, a change in reservoir stage will induce a change in the water level of the aquifer. For the simplest case, assume that the reservoir stage is in equilibrium with the water table in the adjacent aquifer (fig. $2 A$ ). If the reservoir stage decreases (fig. $2 B$ ), water will move from the aquifer to the reservoir, thereby decreasing the aquifer water table and increasing the reservoir stage until the reservoir stage and aquifer water table are again in equilibrium. If the reservoir stage increases (fig. $2 C$ ), water will move from the reservoir to the aquifer, thereby decreasing the reservoir stage and increasing the aquifer water table until the reservoir stage and aquifer water table are again in equilibrium. The aquifer response is further complicated when time-varying changes in reservoir stage are imposed on the system prior to achieving equilibrium. The resulting aquifer response will then be a function of both the new change in reservoir stage and the decaying effects of the previous changes in reservoir stage.

When the sum of the inflows to the reservoir is less than the sum of the outflows, the reservoir stage will decrease because water in storage is being used to meet the withdrawals from the reservoir. A decrease in reservoir stage relative to the 
A.

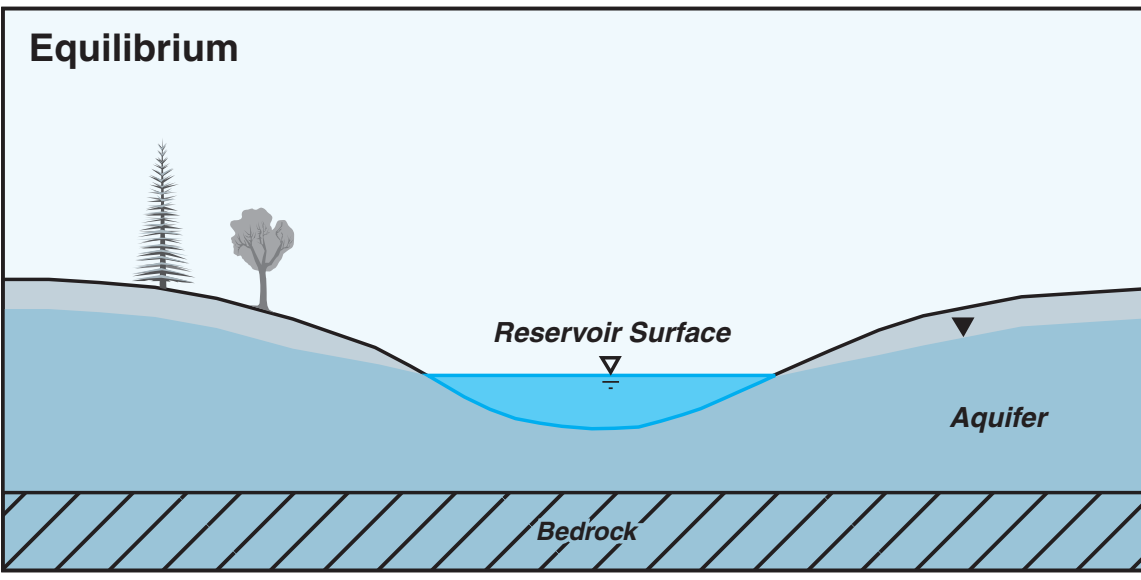

$B$.

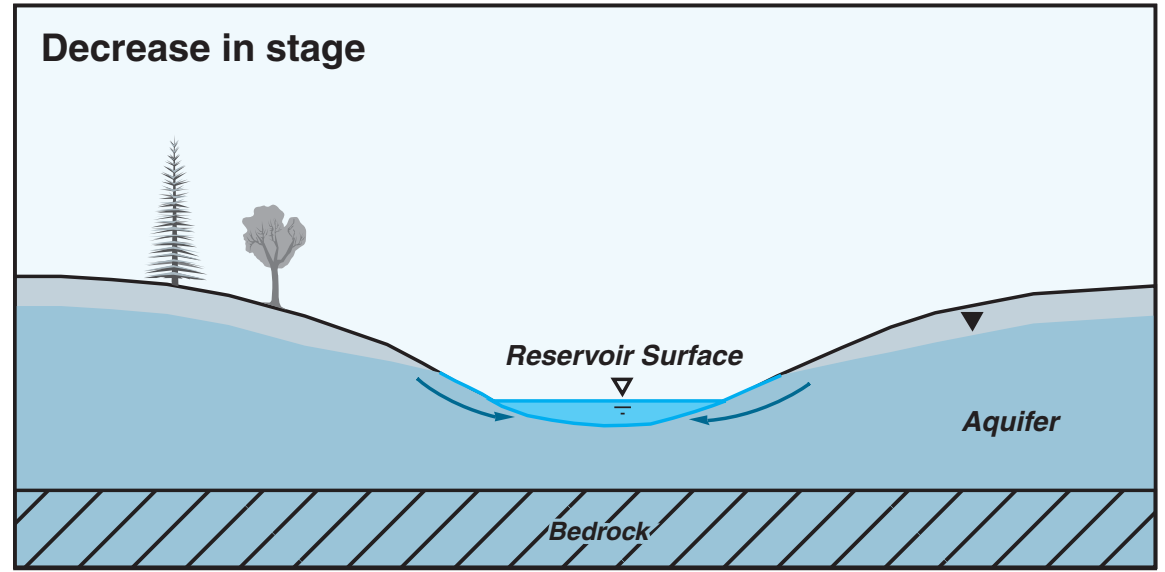

C.

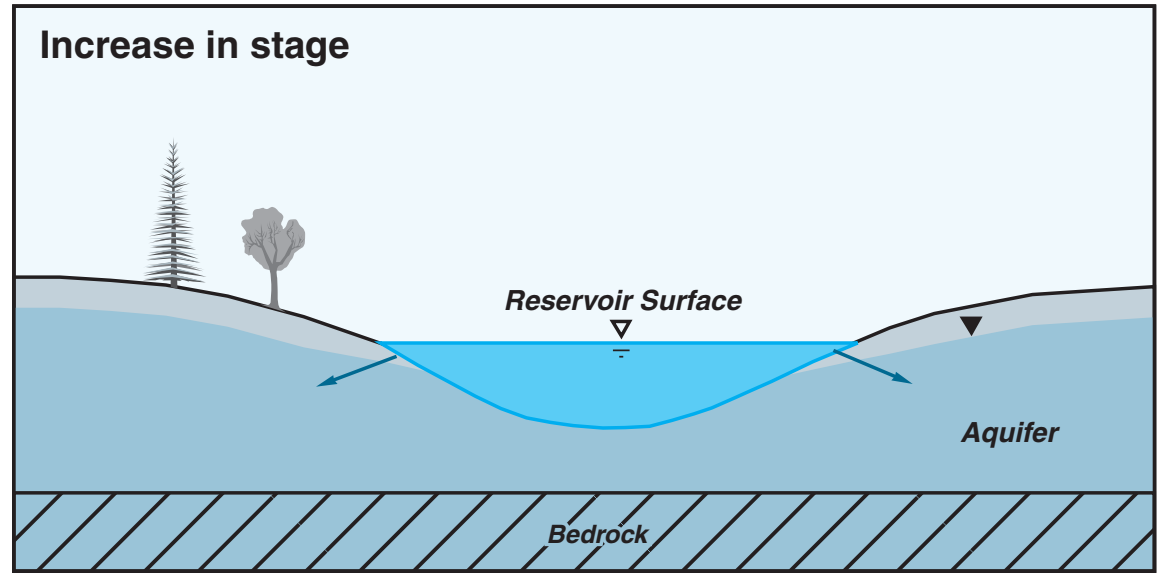

Figure 2. $A$, Reservoir water level at equilibrium with the water table in the surrounding aquifer; $B$, response of the water table to a decrease in the water level of the reservoir relative to the water table; or $C$, to an increase in the water level of the reservoir relative to the water table.

water table in the adjacent aquifer would supplement storage to the reservoir because water will be released from the aquifer to the reservoir (fig. $2 B$ ). As the reservoir is being drawn down and reservoir stage is decreasing, the resulting ground-water contribution from the aquifer to the reservoir could provide additional water that will prevent the reservoir from failing at a yield that would have otherwise caused the reservoir to

\author{
EXPLANATION \\ UNSATURATED \\ SATURATED \\ - FLOW DIRECTION \\ $\underline{\nabla}$ STAGE \\ $\nabla$ WATER TABLE
}




\section{Purpose and Scope}

The purpose of this report is to present the results of the USGS/MassDEP study on the effect of ground-water contributions on estimates of firm yield. The report documents the methodology used to quantify the ground-water contributions to reservoir storage, explains how the methodology was applied to the existing firm-yield-estimator (FYE) model, and analyzes how the modified FYE model can be used to understand the effect of ground-water contributions on estimates of firm yield.

This report identifies and evaluates the applicability of a set of equations that can be used to estimate the contribution of ground water to reservoir storage due to time-varying changes in reservoir stage for reservoir-aquifer systems for which a more detailed, two- or three-dimensional numerical groundwater-flow model is not available. The report discusses (1) the implementation of the set of equations into the existing version of the FYE model, (2) the sensitivity of an estimate of firm yield to changes in the input variables for four hypothetical reservoir-aquifer systems that represent the range of reservoirs and aquifers in Massachusetts, and (3) the potential differences in estimates of firm yield that result from the consideration of this ground-water contribution to reservoir storage for nine reservoir-aquifer systems in Massachusetts previously studied by Waldron and Archfield (2006) that have their shorelines in contact with sand and gravel aquifers. Although numericalmodel simulations were used to determine the applicability of the set of equations and the implementation of the equations, a comparison of the results from the modified FYE model with observed reservoir values is beyond the scope of this report. Furthermore, the firm-yield simulations in this report assume that all the water in usable reservoir storage is available for public supply, and the simulations do not include any consideration for the effect that this yield may have on streamflow downstream from the reservoir.

\section{The Existing Firm-Yield-Estimator Model for Reservoirs in Massachusetts}

To gain a better understanding of the margin between current demands to drinking-water reservoirs and their respective firm yields, MassDEP developed a guidance document that details a procedure to determine the firm yield of a reservoir in Massachusetts that receives water only from surface-water inputs (Massachusetts Department of Environmental Protection, 1996). The procedures in this document were used to develop the Firm-YieldEstimator (FYE) model (Massachusetts Department of Environmental Protection, 2000). Waldron and Archfield (2006) evaluated and modified the procedure used to estimate the reservoir water-balance terms and the firm yield.

Based on the MassDEP FYE guidance document (1996) and the modifications by Waldron and Archfield (2006), the firm yield is computed by solving the monthly water balance (eq. 1) of a reservoir during concurrent records of historical precipitation and streamflow values that include the drought of the 1960s:

$S_{i}=S_{i-1}+A_{w_{i}} Q_{r_{i}}+A_{r_{i}}\left(P_{i}-E_{i}\right)-\alpha_{i} n_{i} Q_{y}-Q_{r_{i}}-Q_{s_{i}}-Q_{o_{i}},(1)$

where

$i \quad$ is the month;

$S_{i} \quad$ is the water in usable storage at the end of the month, in million gallons;

$S_{i-1} \quad$ is the amount of water in usable storage at the end of the previous month, in million gallons;

$A_{w_{i}} \quad$ is the contributing drainage area, in miles squared; 1

$Q_{r_{i}} \quad$ is the streamflow per mile of reservoir drainage, in miles; ${ }^{1}$

$A_{r_{i}} \quad$ is the area of the reservoir surface, in miles squared; 1

$P_{i} \quad$ is the precipitation, in miles;

$E_{i} \quad$ is the evaporation from the reservoir, in miles; ${ }^{1}$

$\alpha_{i} \quad$ is the peak-use factor, dimensionless;

$n_{i} \quad$ is the number of days in the month;

$Q_{y} \quad$ is the yield, in million gallons per day;

$Q_{r_{i}} \quad$ is the required release, in million gallons per month;

$Q_{s_{i}} \quad$ is the uncontrolled spill, in million gallons per month; and

$\mathrm{Q}_{o_{i}} \quad$ is the withdrawal from the reservoir by other users, in million gallons per month.

'Precipitation, streamflow, and evaporation are in units of length and, when multiplied by $A_{\mathrm{r}_{\mathrm{r}}}$, become volumes (in cubic miles) that are converted to million gallons.

Precipitation data were obtained from the nearest climate station; evaporation was estimated using multivariateregression relations developed by Fennessey and Vogel (1996). Streamflow was determined by the QPPQ- (streamflowprobability-probability-streamflow) transform method, which is a method to determine streamflow at an ungaged site by relating the flow-duration curve at a gaged location with the flow-duration curve and basin characteristics at the ungaged location (see Fennessey (1994) for methodology; Waldron and Archfield (2006) provide an evaluation of and modifications to this methodology).

To determine the firm yield for a reservoir or system of reservoirs, equation 1 is solved for each month of the historical record in chronological order. The yield, $Q_{y}$, is initially set equal to zero and is incrementally increased. At each successive increase in yield, the monthly water balance is evaluated for all months of the simulation period. The yield is continually increased until a value is obtained that causes the reservoir to fail. When operating at this yield, the reservoir 
will not be able to meet the withdrawals in all months of the historical record; however, the previous yield value was able to meet the withdrawals for all months of the historical record. This yield — the previous value of $Q_{y}$ that had not resulted in reservoir failure-is considered the firm yield of the reservoir.

Although the firm-yield model does not explicitly account for the contribution of ground water to reservoir storage, the QPPQ-transform method regression equations (Fennessey, 1994) used to determine the surface-water contribution to the reservoir include the soil-retention number, which is a measure of the amount of precipitation retained by the soils in the basin. The soil-retention number is determined by intersecting the drainage-basin boundary for the reservoir with maps of soil and land use. From this intersection, the percentage of each soil and land-use type in the drainage basin of the reservoir can be determined. Each combination of soil group and land cover is assigned a runoff-curve number $(C N)$, which influences the expected runoff for a given amount of rainfall. A composite $C N$ then is calculated by multiplying the fraction of the basin corresponding to a given $\mathrm{CN}$ by that number and adding the weighted $C N$ s. Finally, the soil-retention number, in inches, is estimated from the $C N$ by the use of the following equation (Natural Resources Conservation Service, 1986):

$$
\text { Soil retention number }=\frac{1,000}{C N}-10 .
$$

Therefore, ambient ground-water flow to the reservoir that occurs as a function of soil retention is accounted for in the existing methodology to estimate the firm yield of reservoirs in Massachusetts; however, the contribution of ground water due to time-varying changes in reservoir stage is not. Approximately one-quarter of 70 selected drinking-water reservoirs in Massachusetts have shorelines that are in contact with sand and gravel aquifers.

\section{Determination of Ground-Water Contributions to Reservoir Storage}

An analytical model of hydraulic interaction between a surface-water reservoir and a water-table (unconfined) aquifer was developed to calculate time-varying rates of ground-water inflow to, and storage losses from, surface-water reservoirs. The model is based on an analytical solution to the groundwater-flow equation for the case of one-dimensional groundwater flow in a finite-width aquifer bounded by a linear surface-water feature such as a stream (Rorabaugh, 1964). In this application, the surface-water feature is assumed to be a reservoir. The analytical model is a simplification of complex field conditions that provides approximate flow rates between ground-water and surface-water reservoirs in the absence of more detailed, time-consuming, and expensive, two- and threedimensional numerical ground-water-flow models.

The analytical solution derived by Rorabaugh (1964) to calculate the rate of flow between an aquifer and adjoining linear surface-water body for a constant rate of change in surface-water stage $(h)$ is based on several assumptions, including:

1. The aquifer is of uniform width in the direction perpendicular to the surface-water body and extending to an impermeable boundary (or ground-water divide);

2. Aquifer hydraulic properties are isotropic and homogeneous; and

3. The surface-water feature that forms a boundary to the aquifer is straight, fully penetrates the aquifer, and is in direct hydraulic connection with the aquifer.

The second assumption requires that the transmissivity of the aquifer remains constant with time, which implies that, for a water-table aquifer, changes in water-table elevation are considered negligible when compared to the initial saturated thickness of the aquifer.

Because reservoir stage changes over time, it is necessary to use superposition to calculate total flow rate between the reservoir and aquifer as a function of time; that is, as a function of time-varying reservoir-stage changes. The use of superposition is mathematically acceptable here because the applied ground-water-flow equation is linear. In the superposition approach, incremental changes in the rate of flow between the reservoir and aquifer that occur in response to time-varying reservoir-stage changes are summed to estimate the total flow rate between the reservoir and aquifer.

The calculation of total flow rate, $Q_{T O T_{i}}$, between the reservoir and aquifer at present time $t_{i}$ is:

$$
Q_{T_{i} T_{i}}=Q_{\text {PRESENT }_{i}}+\sum_{j=1}^{t_{i_{o}}} Q_{\text {PAST }_{j}},
$$

where

$Q_{\text {PRESENT }} \quad$ is the flow rate at time $t_{i}$ between the reservoir and aquifer per unit length of reservoir shoreline resulting from the present change in reservoir stage that begins at time $t_{i_{o}}$ and ends at time $t_{i}$, in units of square length per time; and

$Q_{P A S T_{j}} \quad$ is the flow rate between the reservoir and aquifer per unit length of reservoir shoreline resulting from a past change $j$ in reservoir stage that begins at time $t_{j_{o}}$ and ends at time $t_{j}$, in units of square length per time. 
The analytical solution to calculate the flow rate $Q_{P R E S E N T_{i}}$ resulting from the present change in reservoir stage that begins at time $t_{i_{0}}$ and ends at time $t_{i}$ is (Rorabaugh, 1964, eq. 5)

$$
Q_{\text {PRESENT }}=-C_{i} a S\left(1-\frac{8}{\pi^{2}} \sum_{n=1,3 \ldots}^{\infty} \frac{1}{n^{2}} e^{-\frac{n^{2} \pi^{2} T\left(t_{i}-t_{i}\right)}{4 a^{2} S}}\right),
$$

where

$Q_{P R E S E N T_{i}}$ is the flow rate at time $t_{i}$ resulting from the present change in reservoir stage, in units of length

squared per unit time per unit length of reservoir shoreline in contact with the aquifer;

$C_{i} \quad$ is the present rise or fall of the surface-water stage $\left(h_{i}-h_{i_{o}}\right)$ divided by the time $\left(t_{i}-t_{i_{o}}\right)$ over which the rise or fall

has occurred, in units of length per time;

$a$ is the perpendicular distance from the surface-water bank to the lateral boundary of the aquifer, in units of length;

$S \quad$ is the storage coefficient (or specific yield) of the aquifer, which is dimensionless; and

$T \quad$ is the transmissivity of the aquifer, in units of square length per time.

The analytical solution to calculate $Q_{P A S T_{j}}$, the flow rate to the reservoir at present time $t_{i}$ resulting from a past change in reservoir stage that began at time $t_{j_{o}}$ and ended at time $t_{j}$ is (Rorabaugh, 1964, eq. 7)

$$
Q_{P A S T_{j}}=-C_{j} a S\left[\left(1-\frac{8}{\pi^{2}} \sum_{n=1,3, \ldots}^{\infty} \frac{1}{n^{2}} e^{-\frac{n^{2} \pi^{2} T\left(t_{i}-t_{j_{o}}\right)}{4 a^{2} S}}\right)-\left(1-\frac{8}{\pi^{2}} \sum_{n=1,3, \ldots}^{\infty} \frac{1}{n^{2}} e^{-\frac{n^{2} \pi^{2}\left(t_{i}-t_{j}\right)}{4 a^{2} S}}\right)\right],
$$

where

$Q_{P A S T_{j}} \quad$ is the flow rate at present time $t_{i}$ resulting from a past change $j$ in reservoir stage ending at $t_{j}$, in units of length squared per unit time per unit length of reservoir shoreline in contact with the aquifer;

$C_{j} \quad$ is the past rise or fall of the surface-water stage $\left(h_{j}-h_{j_{o}}\right)$ divided by the time $\left(t_{j}-t_{j_{o}}\right)$ over which the past rise or fall had occurred, in units of length per time;

$j \quad$ is the past time step;

$a$ is the perpendicular distance from the surface-water bank to the lateral boundary of the aquifer, in units of length;

$S \quad$ is the storage coefficient (or specific yield) of the aquifer, which is dimensionless;

$T$ is the transmissivity of the aquifer, in units of square length per time.

The summation terms in equations 4 and 5 will approach zero when values of $\left(T\left(t-t_{0}\right) / a^{2} S\right)>2.5$; this can occur when $\mathrm{t}$ becomes relatively large (Rorabaugh, 1964). In the calculation of $Q_{P R E S E N T_{i}}$ (eq. 4), when the value of $\left(T\left(t_{i}-t_{i_{0}}\right) / a^{2} S\right)>2.5$, the flow between the aquifer and reservoir approaches the steady-state solution, $\mathrm{CaS}$ (Rorabaugh, 1964). In the calculation of $Q_{P A S T_{j}}$ (eq. 5), a past change $C_{j}$ in reservoir stage will no longer contribute substantially to the calculation of $Q_{T O T_{i}}$ when $\left(t_{i}-t_{j}\right)>\left(2.5 a^{2} S / T\right)$. For this case, the duration of time between the present time and the past change in reservoir stage becomes so large that the past change in reservoir stage has no substantial effect on the calculation of the flow rate between the reservoir and the aquifer at the present time. Calculation of $Q_{T O T_{i}}$ results in a flow rate per unit time per unit of reservoir shoreline in contact with the aquifer. Therefore, to determine the total volumetric flow rate entering the reservoir at time $t_{i}$ resulting from the present and past changes in reservoir stage, $Q_{T O T_{i}}$ is multiplied by the length of the reservoir shoreline in contact with the aquifer, $L$.

To maintain the assumption that flow between the reservoir and aquifer is horizontal and one-dimensional, the analytical method assumes that ground water is discharging along a stream channel with straight sides (Rorabaugh, 1964); however, few reservoirs have a shape that resembles a stream channel. To understand the effects of geometry on the one-dimensional solution to the ground-water-flow equation, ground-water-flow rates simulated by equation 3 were compared to ground-water-flow rates simulated by a two-dimensional, finite-difference ground-water-flow model for shapes of surface-water bodies that are a more realistic representation of a reservoir shoreline.

In the natural world, the map-view outlines of various ponds and lakes occur in a nearly infinite array of shapes; however, for comparative purposes, 12 simple, surface-water-body shapes were used to generalize the effect of reservoir-aquifer geometry on ground-water-flow rates (fig. 3A). The long-thin line (fig. 3A, shape no. 1) is the shape that is most representative of an idealized stream as described in the assumptions made in the derivation of the analytical solutions of Rorabaugh (1964); the remaining shapes represent various types of deviation from the idealized-stream shape (fig. $3 A$, shapes 2 to 12). 


\section{A. SURFACE-WATER-BODY SHAPES}

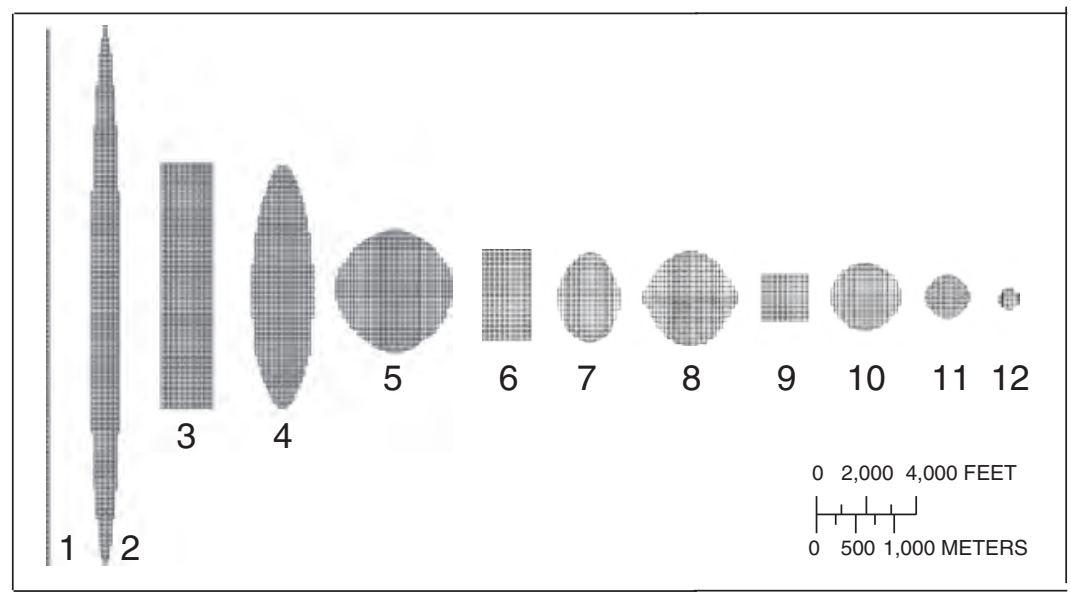

\section{EXPLANATION}

SURFACE-WATER-BODY SHAPE AND IDENTIFIER—Sinusoidal time-varying hydraulic head fluctuation applied to area of shape using the Constant Head Boundary (CHD) Package in the numerical model simulation.

\section{B. MODEL GRID FOR RESERVOIR-AQUIFER SYSTEMS}

\section{EXPLANATION}

SURFACE-WATER-BODY SHAPE 10

MODEL GRID

BOUNDARY OF THE ACTIVE MODEL AREA

LENGTH OF RESERVOIR SHORELINE IN CONTACT WITH THE AQUIFER (L)

DISTANCE FROM THE RESERVOIR SHORELINE TO THE AQUIFER (a)
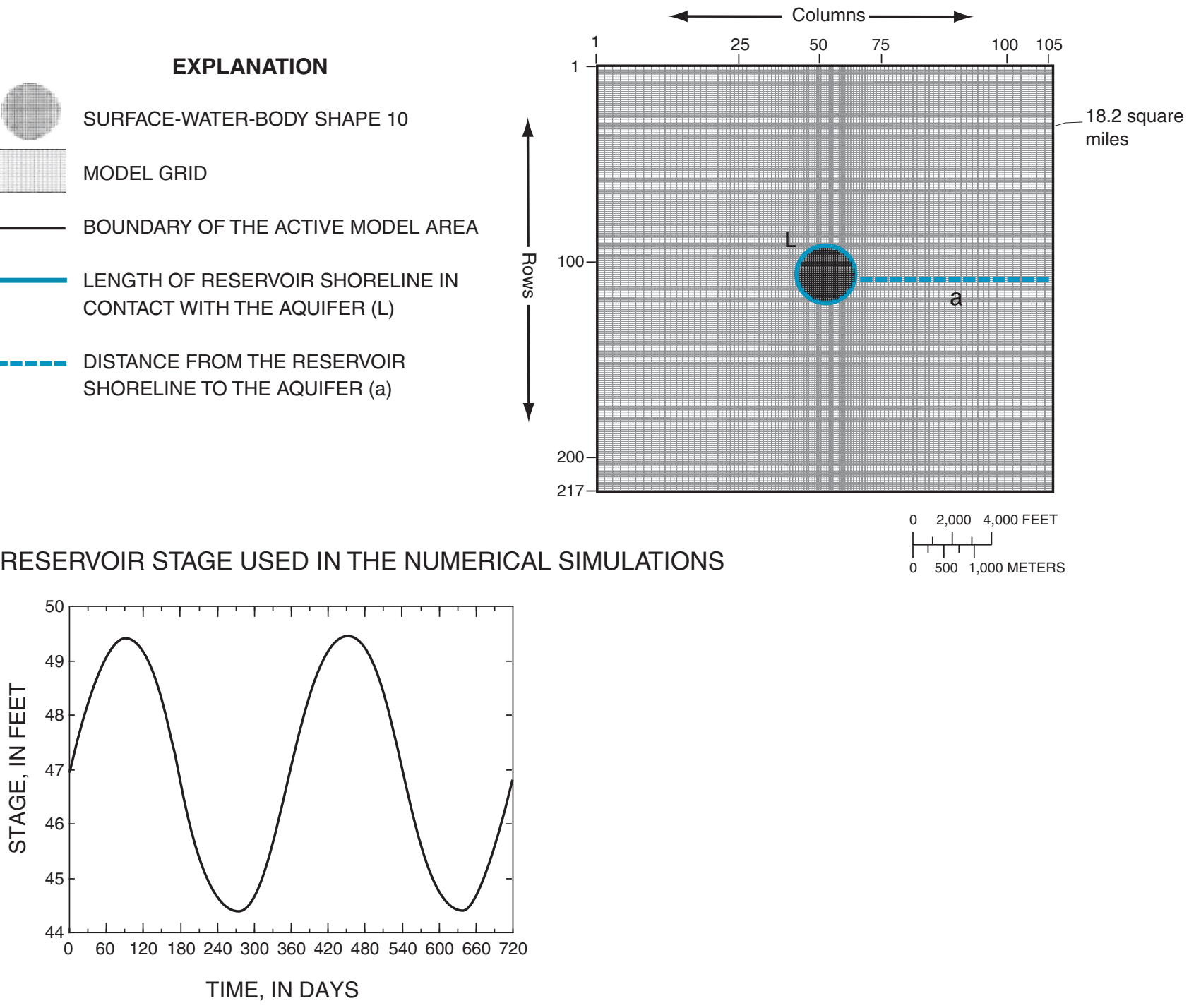

Figure 3. A, Surface-water-body shapes; $B$, with underlying model grid (shown with surface-water-body shape 10) for reservoiraquifer systems; and $C$, reservoir stage fluctuations used to evaluate the effects of reservoir-aquifer geometry on the analytical solution to the ground-water flow equation derived by Rorabaugh (1964). 


\section{Numerical-Model Simulations of Idealized Reservoir-Aquifer Geometries}

A finite-difference ground-water-flow model was used to calculate transient water budgets for idealized reservoiraquifer geometries. The finite-difference ground-water flow model used for these comparisons was MODFLOW-2000 (Harbaugh and others, 2000). The idealized reservoir-aquifer geometries are different surface-water-body shapes (fig. $3 A$ ) incorporated into an underlying numerical model (fig. $3 B$ ) with identical hydrologic and spatial properties.

Each idealized reservoir-aquifer geometry (fig. $3 B$ ) was simulated using an identical underlying numerical-model grid covering an area of 18.2 square miles (fig. $3 B$ ). A transient, one-layer (50-ft thick) model consisting of 24 stress periods of 30 days in length (total simulated time of 720 days; two 360-day years) was made to simulate the water budget for each of the 12 idealized-shape hydrologic systems (fig. $3 B$ ) that include one of the shapes shown in figure $3 A$. The variable-spaced grid consists of 217 rows of increasing cellwidth (102.6 ft at center, increasing on the left to $396.8 \mathrm{ft}$ and on the right to $408.8 \mathrm{ft}$ ) along the row and 105 columns of equal cell height (100.4 ft) down the column. A uniform value of 45 feet per day was specified for horizontal hydraulic conductivity. For each idealized-shape hydrologic system, the model was run under both confined and unconfined aquifer conditions. Values of storativity $S$ were adjusted so that MODFLOW would calculate the same storage capacity and therefore produce similar water budgets when the model was run as a confined system compared to when the model run as an unconfined system. For unconfined conditions, a value for specific yield $S_{y}$ is used by MODFLOW to calculate storage capacity. Here the value of $S_{y}$ was set equal to 0.2 $\left(S_{y}=S=0.2\right.$ ). For confined conditions, MODFLOW uses a value of specific storage $S_{S}$ to calculate storage capacity. To determine a value for specific storage to yield a storage capacity similar to that for the unconfined case, the equation for a confined aquifer, $S=b S_{S}$ (Barlow and Moench, 1998; Fetter, 1994), where $S$ equaled 0.2 and aquifer thickness $b$ was $50 \mathrm{ft}$. A $S_{s}$ value of 0.004 was used for confined conditions. The computed flow rates between the reservoir and aquifer resulting from the unconfined simulations were used to evaluate the equations because there was no substantial difference between the unconfined and confined simulation results for the 12 idealized shapes.

The Constant Head Boundary (CHD) Package in MODFLOW-2000 (Harbaugh and others, 2000) was used to specify hydraulic head within the area corresponding to each different idealized surface-water-body shape (fig. $3 A$ ) for the length of the simulation. Numerical values that resemble a sinusoidal fluctuation when graphed against time were used to simulate the magnitude of the time-varying hydraulic head specified in the CHD input file (fig. $3 C$ ). The sinusoidal fluctuation, divided into segments corresponding to simulated stress periods 1 through 12 (year 1), had an initial value of $47.0 \mathrm{ft}$, a high value of $49.5 \mathrm{ft}$, a low value of $44.5 \mathrm{ft}$, and a final value of $47.0 \mathrm{ft}$. The same head pattern was repeated for simulated stress periods 13 to 24 (year 2). No other stresses, such as pumping or recharge, were simulated. A value of 47.0 $\mathrm{ft}$ was used elsewhere as starting head in the surrounding model cells.

\section{Analytical Simulations of Idealized Reservoir- Aquifer Geometries}

The idealized-shape hydrologic systems (fig. $3 B$ ) and 2-year sinusoidal fluctuation in reservoir stage (fig. $3 C$ ) were used to analytically simulate flow rates between the reservoir and aquifer using the equations developed by Rorabaugh (1964). Although the numerical-model simulations track the flow of water between each cell over the entire simulated area to compute the total volumetric flow rate at the reservoiraquifer interface, the equations parameterize the geometry of the aquifer-reservoir geometries through the specification of $L$, the length of reservoir shoreline in contact with the aquifer and $a$, the distance from the reservoir shoreline to the aquifer boundary (fig. 3B). The values of $L$ and $a$ were estimated from the numerical-model grid (fig. $3 B$ ), where $L$ was the perimeter of the idealized shape (because the entire shoreline of each surface-water body was in contact with the aquifer) and $a$ was the average of several measured distances from the shoreline of the surface-water body to the aquifer boundary. The values of transmissivity $T$ and storativity $S$ used in the analytical simulations were equivalent to the values used in the numerical-model simulations: 2,250 feet squared per day $(\mathrm{ft} 2 / \mathrm{d})$ and 0.2 , respectively.

\section{Effect of Reservoir Shape on the Flow Rate between the Reservoir and Aquifer}

The timing and magnitude of the volumetric flow rates resulting from the numerical and analytical simulations of the reservoir-aquifer geometries were compared for the second year of the simulation period. The simulated volumetric flow rates were converted to units of million gallons per day and divided by $L$ to obtain a volumetric flow rate in million gallons per day per foot of reservoir shoreline. Idealized shape 1 (fig. $3 A$ ) — the shape most resembling a stream channel-satisfies the assumptions used by Rorabaugh (1964) to derive the equations. For this case, the numerically and analytically simulated volumetric flow rates were nearly identical with respect to the timing and the magnitude of the flow rates (fig. 4).

When the surface-water-body shape deviated from shape 1 (fig. $3 A$ ), the difference between the timing of the numerically simulated and analytically simulated flow rates appear to be related to the ratio of $a$ (the distance from the reservoir shoreline to the aquifer boundary) to $L$ (the perimeter of the idealized shape) (fig. 4). As the ratio of $a$ to $L$ increased ( $L$ smaller than $a$ ), the flow rates resulting from the numerical- 


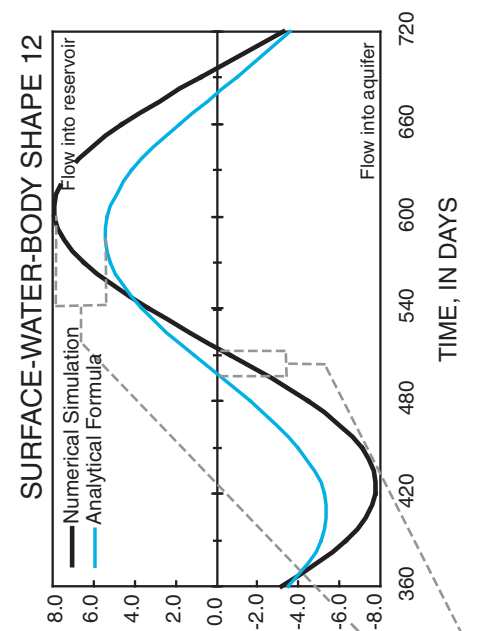

SABO NI 'S

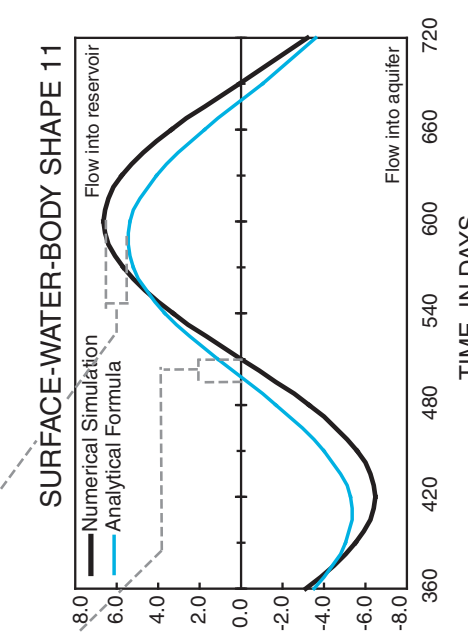

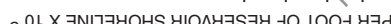

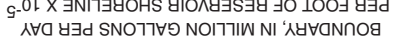

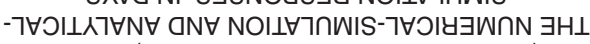

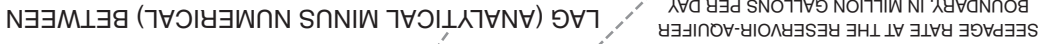

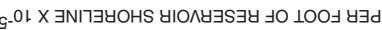

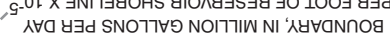

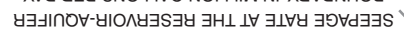

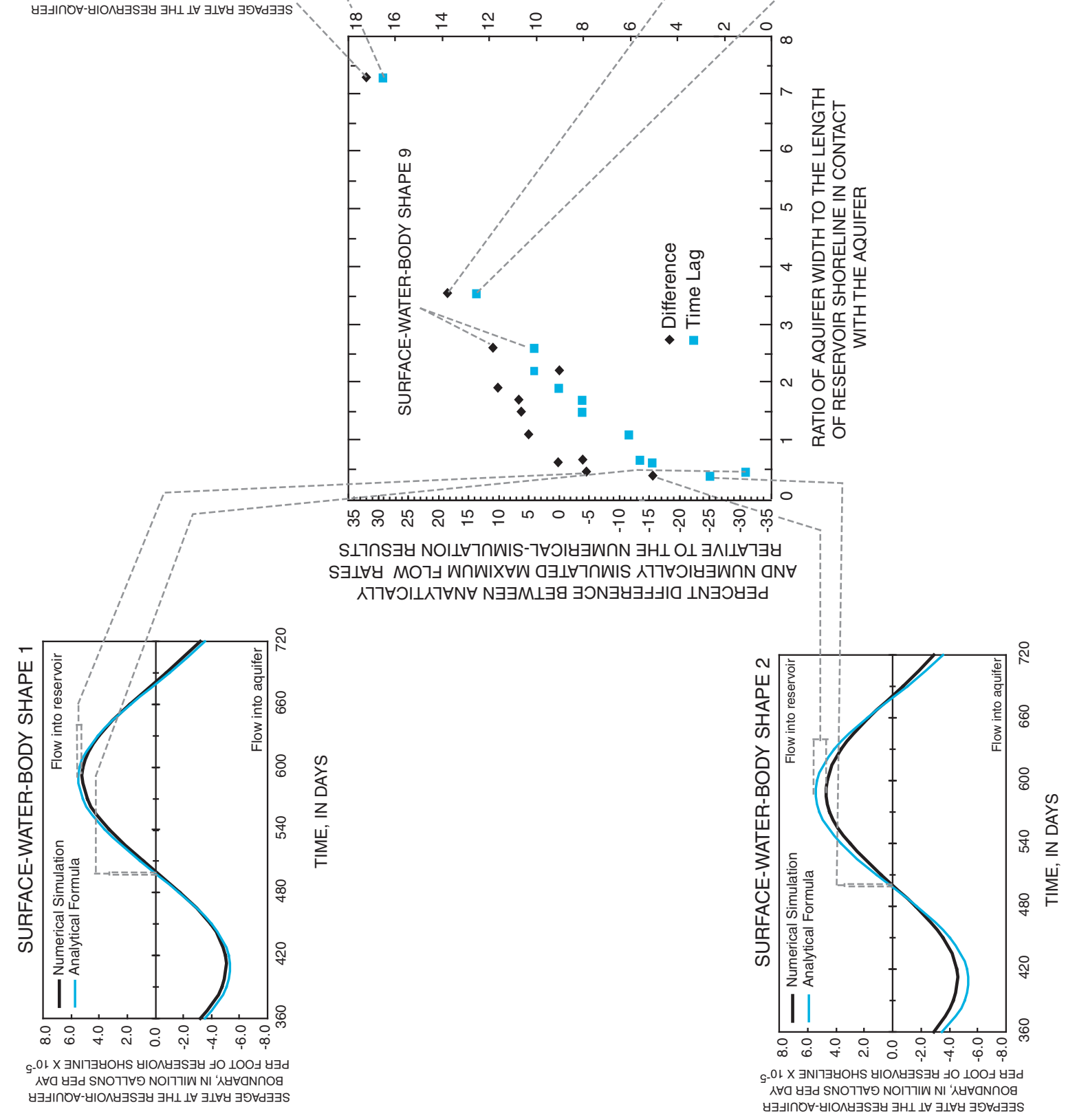


model simulations responded more slowly to the sinusoidal time-varying changes in reservoir stage than the resulting flow rates from the analytical simulations (fig. 4).

With the exception of idealized shapes $2,9,11$, and 12 , the differences in magnitude between the numerically simulated and analytically simulated volumetric flow rates were within \pm 10 percent (fig. 4 , center graph). For values of $a$ to $L$ less than 1 ( $L$ larger than $a$ ), the analytically simulated flow rates were greater than the numerically simulated flow rates; for values of $a$ to $L$ greater than 1 ( $L$ smaller than $a$ ), the analytically simulated flow rates were less than the numerically simulated flow rates. Selected reservoir-aquifer geometries are shown in figure 4 to illustrate the differences between the flow rates determined from the numerical and analytical simulations.

The four idealized shapes that had a greater than \pm 10 percent difference between the two volumetric flow rates also were the reservoir-aquifer geometries with the most extreme values of $a$ to $L$. Furthermore, the largest percent differences do not appear to be related to the shape of the reservoir shoreline but, rather, the values of $a$ to $L$ that resulted from the reservoir-aquifer geometry: idealized shape 2 is an ellipse, idealized shape 9 is a square, and idealized shapes 11 and 12 are circles (fig. $3 A$ and fig. 4). Reservoir-aquifer geometries with values of $a$ to $L$ between approximately 0.5 and 3.5 have simulated flow rates within \pm 10 percent (fig. 4).

Differences between the magnitude and timing of the flow rates resulting from the numerical and analytical solutions were expected because of the inherent differences between the numerical and analytical simulations. The equations (analytical simulations) assume a one-dimensional, horizontal flow, whereas the numerical simulations account for two-dimensional flow between the surface-water-body shapes and an aquifer. Additionally, the equations represent only the reservoir-aquifer geometry through the parameters $a$ and $L$, and only the time-varying changes in reservoir stage determine the timing of the flow rates. Conversely, the numerical simulation accounts for the flow of water between each cell in the model grid (fig. $3 B$ ), and the timing and magnitude of the flow rate is not only a function of the time-varying changes in reservoir stage but also the integration of the fluxes between all cells in the model grid. Despite the simple geometric parameterization of the reservoir-aquifer interaction and the assumption of one-dimensional flow in the analytical simulations, the analytically simulated flow rates were reasonably comparable to the numerically simulated flow rates with respect both to the magnitude and timing of the flow rates for most of the idealized shapes. Furthermore, the shape of the reservoir did not appear to affect the agreement between the numerically simulated and analytically simulated flow rates; rather, the size of aquifer (represented by $a$ ) relative to the size of the reservoir (represented by $L$ ) appears to explain much of the variability in the agreement between the numerically simulated and analytically simulated flow rates for the various reservoir-aquifer geometries.

\section{Application of the Ground-Water-Flow Equations to the Firm-Yield-Estimator Model}

Although the analytical equations developed by Rorabaugh (1964) were derived by assuming one-dimensional, horizontal flow between an aquifer and a stream, the equations provide a reasonable approximation of numerically simulated flow rates between a reservoir and aquifer (within \pm 10 percent) when the ratio of $a$ to $L$ is between approximately 0.5 and 2.3, regardless of the shape of the reservoir shoreline in contact with the aquifer (figs. $3 A$ and 4 ). Additionally, the analytical equations require only five inputs to estimate the flow rate between the reservoir and aquifer: (1) $a$, the average distance from the reservoir shoreline to the aquifer boundary (fig. $3 B$ ); (2) $L$, the length of the reservoir shoreline in contact with the aquifer (fig. $3 B$ ); (3) $T$, aquifer transmissivity; (4) $S$, aquifer storativity; and (5) the relation between reservoir storage and reservoir stage, which is used to determine the timevarying changes in reservoir stage. Therefore, the analytical equations developed by Rorabaugh (1964) were incorporated into the existing FYE model.

The modified FYE model was incorporated into the existing relational database structure developed by Waldron and Archfield (2006). The generalized framework for the modified FYE model is shown in figure 5. For the case where a reservoir is not in contact with an aquifer, the FYE model remains unchanged. When a reservoir is in contact with an aquifer, the five inputs must be estimated in addition to the data requirements of the original FYE model.

The reservoir water balance, including the ground-water contribution to reservoir storage due to time-varying changes in reservoir stage, can be expressed as

$$
\begin{aligned}
S_{i}=S_{i-1}+A_{w_{i}} Q_{r_{i}}+ & A_{r_{i}}\left(P_{i}-E_{i}\right) \pm \\
& Q_{G W_{i}^{-}}-\alpha_{i} n_{i} Q_{y}-Q_{r_{i}}-Q_{s_{i}}-Q_{o_{i}},
\end{aligned}
$$

where

$$
\begin{aligned}
Q_{G W_{i}} \quad \text { is the volume of water that moves between } \\
\text { the reservoir and aquifer due to the present } \\
\text { change in reservoir stage during the month } \\
\text { and the time varying past changes in } \\
\text { reservoir stage over previous months, in } \\
\text { units of million gallons. }
\end{aligned}
$$

Although the change in reservoir stage over month $i$ is assumed to be constant with time, the resulting flow rate is not (eqs. 4 and 5). The flow rate is a function of the difference between $t_{i}$ and $t_{i_{o}}$, and time $t_{i}$ and $t_{j_{o}}$, which will be different for each point in time within the month. Therefore, the inclusion of the term $Q_{G W_{i}}$ in the water balance of a given reservoir implies that the resulting volumetric term $Q_{G W_{i}}$ is the integration of the flow rates between the reservoir and aquifer over all time $t$ within the present month $i$ : 
where

$$
Q_{G W_{i}}=\int_{0}^{t_{i}-t_{i_{o}}} Q_{T O T^{d t_{i}}},
$$

$t_{i} \quad$ is the number of days from the start of the simulation to the end of the present change in reservoir stage, and

$t_{i_{o}} \quad$ is the number of days from the start of the simulation to the beginning of the present change in reservoir stage.

Equation 7 is an integration of equation 3 and requires the calculation of the ground-water flow resulting from all past timevarying changes as well as the present change in reservoir stage at all values of $t$ throughout month $i$. A closed-form, analytical solution to equation 7 does not exist; hence, it is not possible to directly implement equation 7 into the FYE model. For this reason, an approximation to equations 3 through 5 and equation 7 was required to determine the flow rate during the month.

An additional challenge to the implementation of the equations arises from the feedback between reservoir storage and reservoir stage. To determine $C_{i}$ and, in turn, $Q_{G W_{i}}$, the reservoir stage at the end of the present month must be known; however, because the reservoir stage is estimated from the reservoir storage-stage relation, the stage in the reservoir is not known until the FYE model calculates the reservoir storage at the end of the present month. Yet, the reservoir storage at the end of the present month cannot be calculated until the values of the water-balance terms -including $Q_{G W_{i}}$-are determined (eq. 5). An iterative loop was added to the modified FYE model to address this within-month feedback between reservoir storage, reservoir stage, and $Q_{G W_{i}}$

\section{Modifications to the Ground-Water-Flow Equations}

To approximate the equations that calculate $Q_{G W_{i}}, Q_{P R E S E N T_{i}}$ and each $Q_{P A S T_{j}}$ are computed at the middle of the month $(t$ approximately equal to 15 days). This flow rate is assumed to represent the average flow rate between the reservoir and aquifer during the present month $i$. The modified equations for $Q_{P R E S E N T_{i}}, Q_{P A S T_{j}}$, and $Q_{G W_{i}}$ are

$$
\begin{aligned}
& Q_{P R E S E N T_{i}}=-C_{i} a S\left(1-\frac{8}{\pi^{2}} \sum_{n=1,3, \ldots}^{\infty} \frac{1}{n^{2}} e^{\left.-\frac{n^{2} \pi^{2} T\left(\frac{t_{i}-t_{i_{o}}}{2}\right)}{4 a^{2} S}\right)}\right.
\end{aligned}
$$

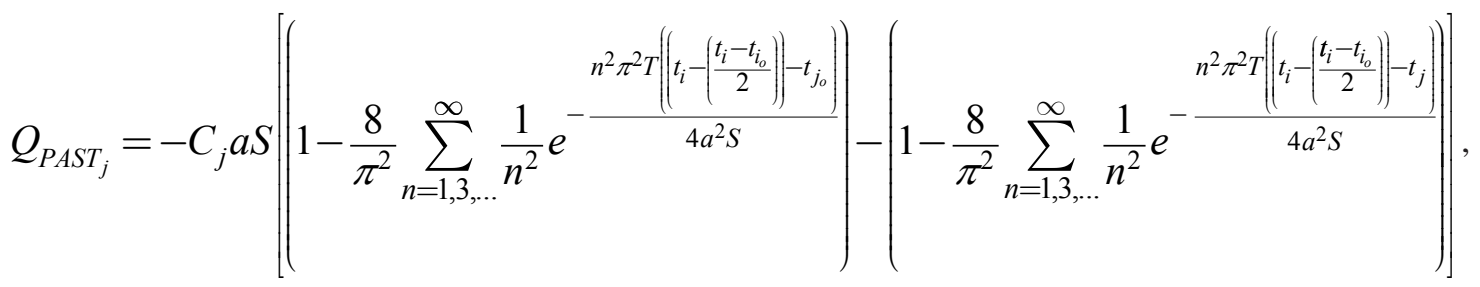

$$
\begin{aligned}
& \text { and } Q_{G W_{i}}=(L)\left(Q_{T O T}\right)\left(t_{i}-t_{i_{o}}\right) \text {. }
\end{aligned}
$$

To verify that the modified equations were applied correctly to the FYE model, numerical-model simulations of flow rates along with reservoir water levels were compared to FYE-simulated flow rates and reservoir water levels for four idealized hydrologic systems patterned after four reservoir-aquifer systems in Massachusetts (fig. 6): Reservoir A, patterned after Fitchburg Reservoir in Ashby; Reservoir B, patterned after Morse Reservoir in Leominster; Reservoir C, patterned after Bearhole Reservoir in West Springfield; and Reservoir D, patterned after Millham Reservoir in Marlborough. A 24-month (2-year) period-April 1975 through March 1977—-that represented normal hydrologic and climatic conditions was used to simulate flow rates and water levels in the reservoirs. A 2-year simulation provided sufficient change in reservoir storage to compare the simulated ground-water-flow rates. Real reservoir-aquifer systems provided input variables that represent values in Massachusetts; however, because the simulations are an oversimplified representation of the actual reservoir-aquifer geometry, the numerically and FYE-simulated flow rates and water levels were not intended to reproduce actual flow rates and water levels that occurred during the simulation period. 


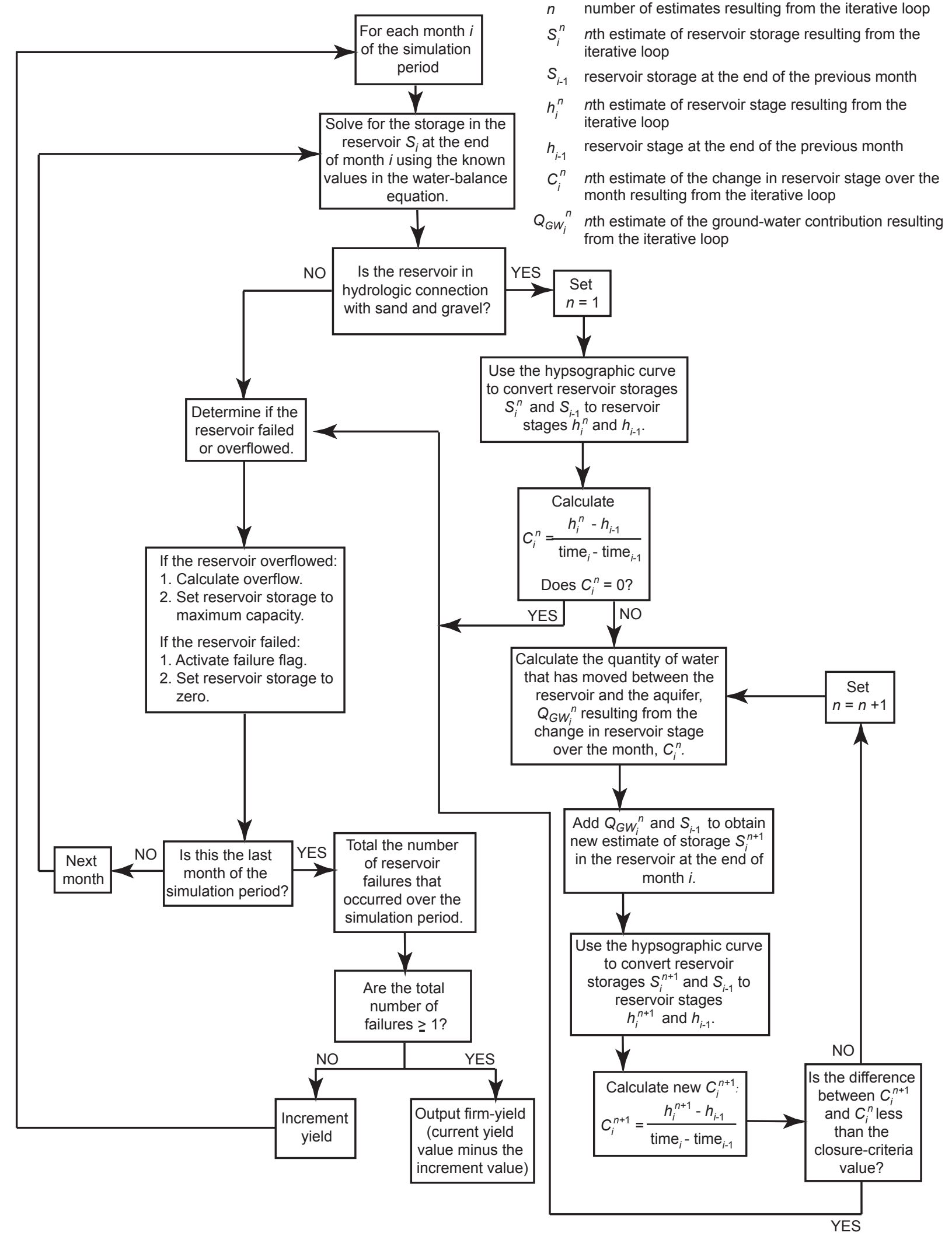

Figure 5. Flow chart of the modified firm-yield-estimator model. 


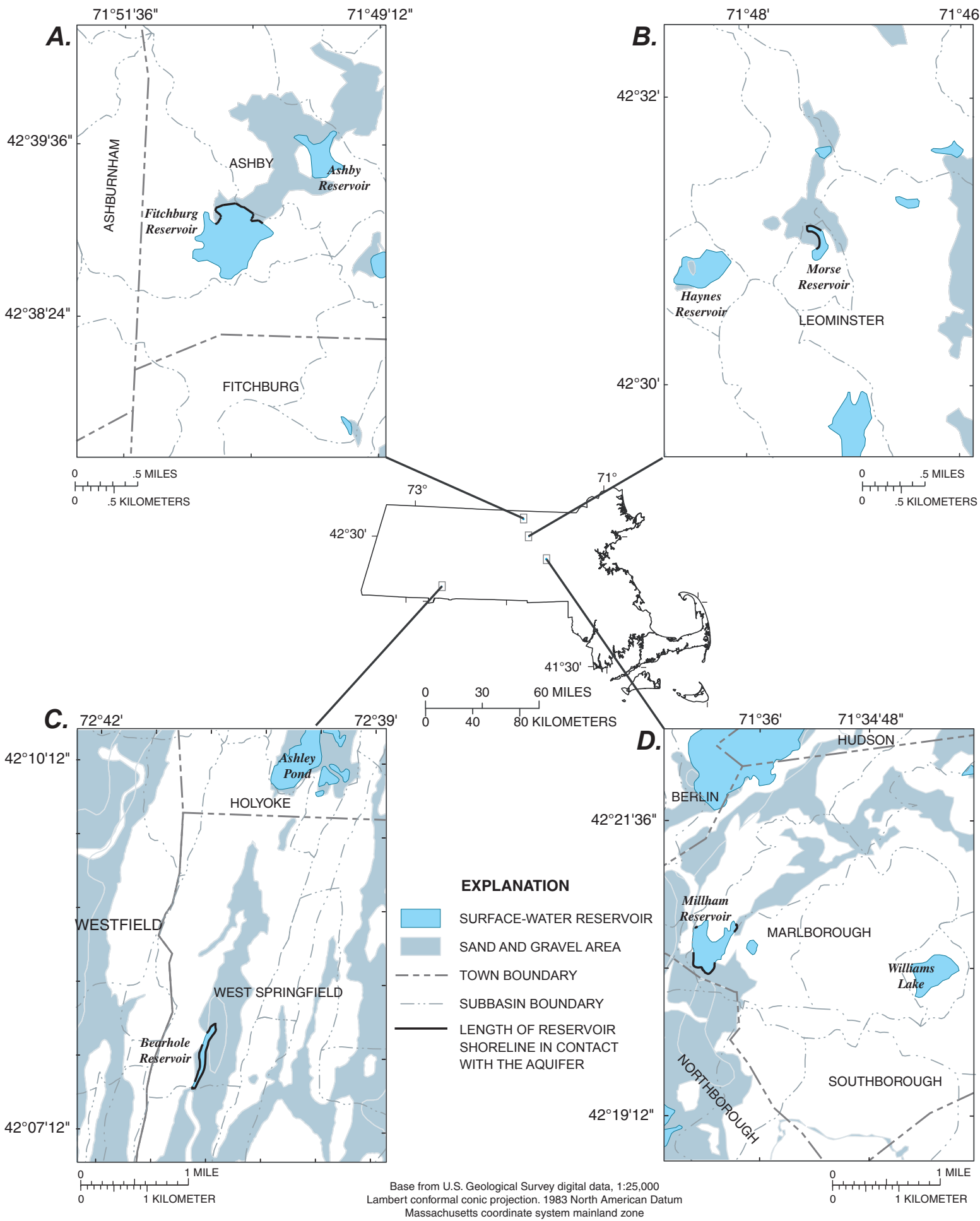

Figure 6. Locations of four reservoir-aquifer systems in Massachusetts: $A$, Fitchburg Reservoir; $B$, Morse Reservoir; $C$, Bearhole Reservoir; and $D$, Millham Reservoir. 


\section{Numerical-Model Simulations of Ground-Water- Flow Rates and Reservoir Water Levels}

Reservoirs A through D were simulated by a transient one-layer model, and the layer type was specified as convertible between confined and unconfined. If a simulated head was above the top of the layer, it functioned as a confined layer; if the simulated head was below the top of the layer, it functioned as an unconfined layer. The reservoirs were simulated as a high transmissivity zone. Model grids were composed of cells $50 \mathrm{ft}$ square and were developed to simulate closely the physical volumes of the reservoir and the sand and gravel aquifer of each respective system. The 50-ft square dimension also provided reasonable numerical solution times.

All terms in the water-balance equation (eq. 6), with the exception of $Q_{G W_{i}}$, were applied uniformly within each stress period. Monthly stress periods corresponded to the actual number of days per given month (28 to 31 days). To simplify the application of stresses to the model, the sum of the known inflows to the reservoir was applied as an injection well in the reservoir area, and the sum of the known outflows was applied as a pumping well in the reservoir area (fig. 7).

To ensure the geometry did not affect the comparison between the simulations, the aquifer and reservoir were represented as rectangles (large streams) that extended the length of the aquifer, just as the idealized stream shape (fig. $3 A$, shape no. 1). The length of the reservoir shoreline was equal to the length-dimension of the aquifer, having length equal to the approximate length of the actual reservoir shoreline in contact with the aquifer (fig. 7). This distance was estimated from Geographic Information System (GIS) digital data layers of hydrography in Massachusetts at a 1:100,000 scale intersected with GIS digital data layers of surficial geology in Massachusetts at a 1:250,000 scale (Office of Geographic and Environmental Information (MassGIS), 2004a; Office of Geographic and Environmental Information (MassGIS), 2004b). The surface area and capacity of the reservoir were obtained from Waldron and Archfield (2006). To determine the width of the reservoir area (fig. 7), the surface area of the reservoir was divided by the length of the reservoir shoreline in contact with the aquifer (table 1). The capacity of the reservoir was divided by the surface area to obtain a depth for the reservoir (table 1). Therefore, idealized reservoir dimensions were used in the simulations.

The surface area of the aquifer also was estimated from GIS digital data layers of hydrography in Massachusetts at a 1:100,000 scale intersected with GIS digital data layers of surficial geology in Massachusetts at a 1:250,000 scale (Office of Geographic and Environmental Information (MassGIS), 2004a; Office of Geographic and Environmental Information (MassGIS), 2004b). The width of the aquifer area was determined by dividing the surface area of the aquifer by the length of the reservoir shoreline in contact with the aquifer. The analytical equations assume that the reservoir fully penetrates the aquifer (Rorabaugh, 1964); therefore, the thickness of the aquifer was specified as equivalent to the depth of the reservoir in the simulations (table 1), although this assumption may be not true for all real reservoir-aquifer systems.

Hydrologic atlases were used to estimate an aquifer transmissivity for reservoirs B, C, and D (Brackley and Hanson, 1977). Because no other hydrologic information was available for the aquifers associated with reservoirs A, B, and $\mathrm{C}$, specific yield values for the reservoir and aquifer were 1 and 0.2 , respectively. Due to the simulated geometry and inflow and outflow volumes applied to the reservoir, a high hydraulic conductivity value $(5,000,000 \mathrm{ft} / \mathrm{d})$ was applied to reservoirs A through $\mathrm{D}$ to simulate a flat water surface over the area of the reservoir. Reservoir D is located in an area for which a detailed ground-water-flow model has been developed and, therefore, recent estimates of the transmissivity and specific yield of the aquifer were available (DeSimone, 2004). Specific-yield values of 1 and 0.18 were specified for reservoir $\mathrm{D}$ and the aquifer, respectively (table 1).

\section{Modified Firm-Yield-Estimator Model Simulations of Ground-Water-Flow Rates and Reservoir Water Levels}

Reservoirs A through D were simulated over the same 2-year period (April 1975 through March 1977) as the numerical-model simulations. The relation between reservoir storage and reservoir stage was determined assuming a rectangularshaped reservoir; the FYE-model simulations represented the surface area of the reservoir as constant for all values of reservoir storage, and the relation between reservoir stage and reservoir storage as linear. The values of aquifer transmissivity $T$, aquifer storage coefficient $S$, aquifer width $a$, and length of reservoir shoreline in contact with the aquifer $L$ were equivalent to the values used in the numerical-model simulations (table 1).

\section{Comparison of Simulated Ground-Water-Flow Rates and Reservoir Water Levels}

Average ground-water-flow rates and water levels resulting from the numerical and FYE-model simulations are compared in figure 8 . The FYE simulation calculates the flow rate between the reservoir and aquifer at the middle of the month and assumes this flow rate represents the average flow rate over the entire month. The numerical simulation calculates the flow rate between the reservoir and aquifer at 14 unequal time steps within each month. Therefore, the average flow rate between the reservoir and aquifer was computed for each month of the numerical simulation and compared to the flow rate simulated by the FYE model (fig. 8A). The water levels calculated by the FYE simulation are the levels that result from the stresses applied during the month, including the inflow or outflow of ground water that has taken place. Therefore, the resulting water level represents the water level 


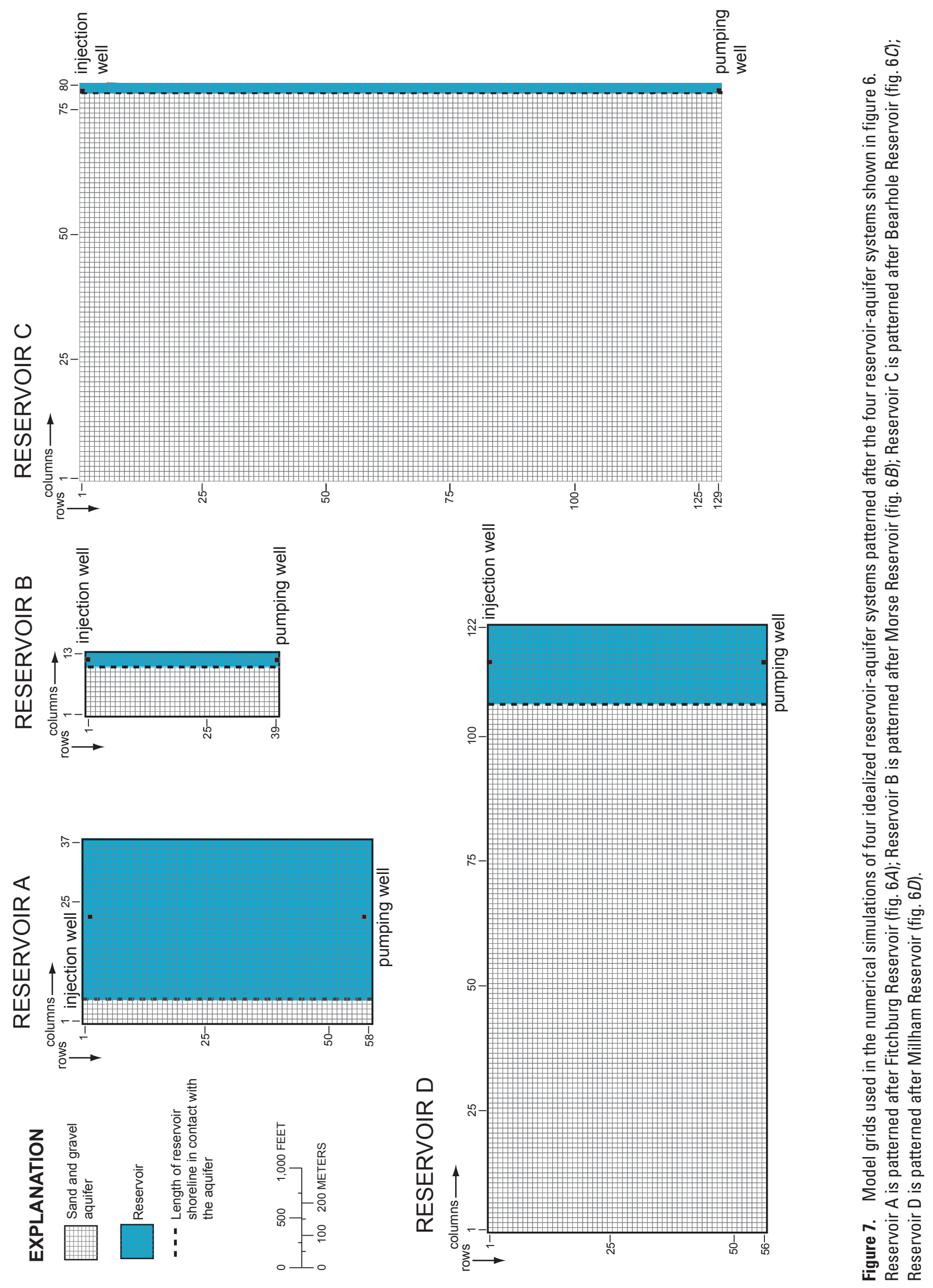




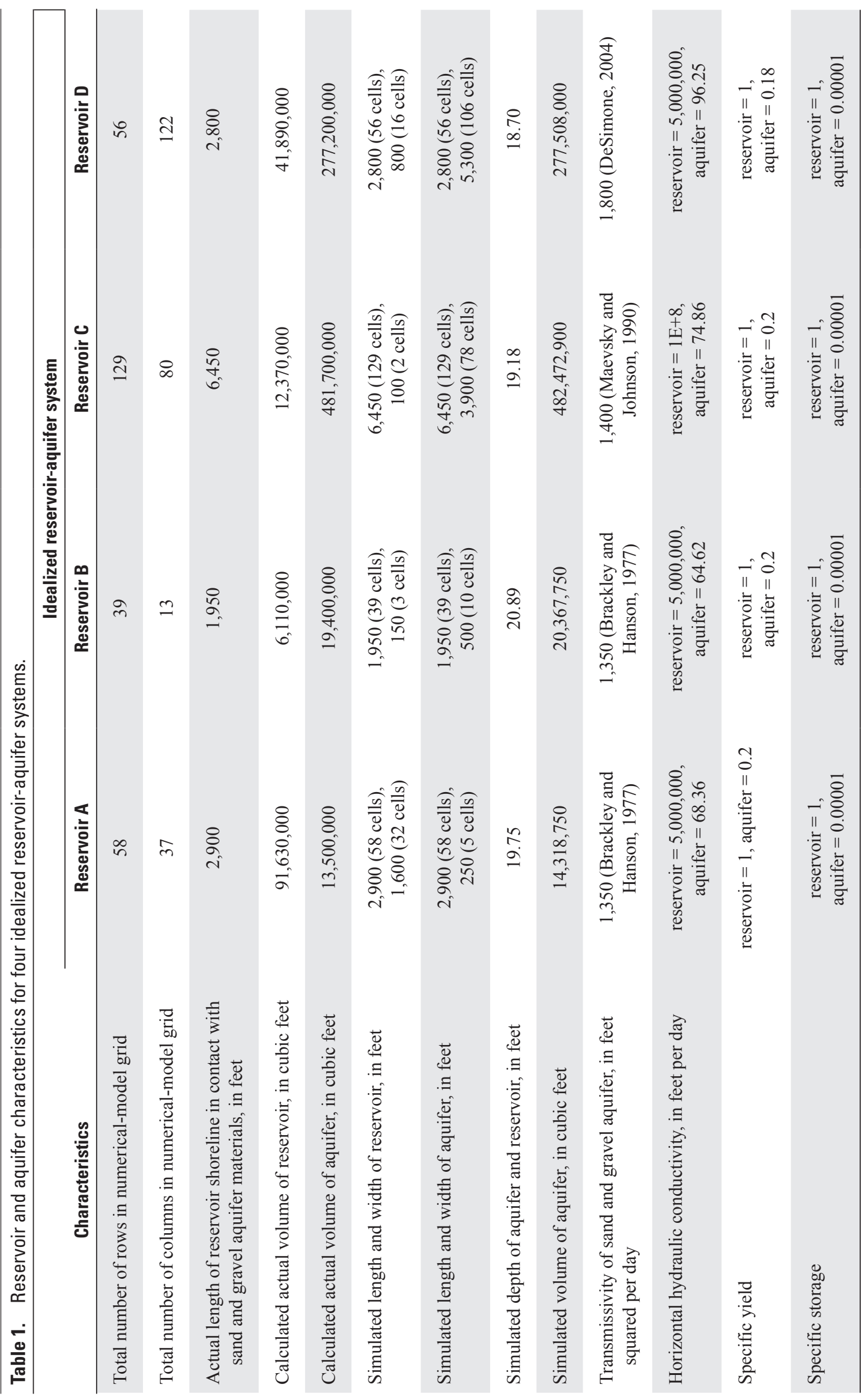


in the reservoir at the end of the month and is compared to the water level from the final time step in the numerical simulation (fig. 8B).

The two simulated, average ground-water-flow rates and reservoir water levels show close agreement (fig. 8). The largest differences between the numerically and FYE-simulated average flow rates were less than 0.04 million gallons per day (Mgal/d) and are present at the peaks and troughs (fig. 8). The largest differences between the numerically and FYE-simulated water-level were less than $0.07 \mathrm{ft}$. For the majority of the simulation period, the differences between simulated water levels and simulated flow rates were less than $0.01 \mathrm{ft}$ and 0.01 $\mathrm{Mgal} / \mathrm{d}$, respectively (fig. 8).

The comparisons between numerical and FYE-model simulations of ground-water-flow rates between the reservoir and aquifer and reservoir water levels appear to indicate that the modified Rorabaugh (1964) equations were incorporated into the FYE model appropriately. Furthermore, the results of the comparisons indicate the calculation of the total monthly contribution of ground water (assuming a constant, average ground-water-flow rate) compares well with numerically simulated, average ground-flow rates.

\section{Iterative Loop to Calculate the Change in Reservoir Stage}

The FYE model computes the reservoir storage at the end of each month in the simulation to determine if the usable storage in the reservoir is able to meet the demand to the reservoir. The tracking of reservoir storage at successive yields is ultimately how the firm yield of the reservoir is determined. To convert reservoir storage to reservoir stage, a bathymetric survey of the reservoir can be used to establish a continuous stage-storage relation from which one can interpolate a reservoir stage from a known reservoir storage. To enable the FYE model to track reservoir stage, the modified FYE model requires the entry of polynomial coefficients that provide a continuous function describing the stage-storage relation.

At the beginning of the simulation, the FYE model assumes the reservoir storage and stage is at a maximum (Massachusetts Department of Environmental Protection, 1996). As the simulation steps forward in time, past changes in reservoir stage will contribute to the calculation of $S_{i}$ (eq. 9). Any past change in reservoir stage will have already been determined during the month when that change took place. The present ground-water contribution resulting from this past change in stage is only dependent on the duration of time that has passed between the past change and the present time. For this reason, the volume of water that exchanges between the reservoir and aquifer due to past changes in reservoir stage, $\Sigma Q_{P A S T_{j}}$, in present month $i$ (eq. 9) can be determined outside of the iterative loop. Therefore, only $C_{i}$ and the resulting $Q_{P R E S E N T_{i}}$ terms in the ground-water-flow equations that determine $Q_{G W_{i}}$ are dependent upon the results of the iterative loop.
To provide the initial estimate of the change in reservoir stage $C_{i}{ }_{i}$, where the superscript denotes the estimate of $C_{i}$ obtained from the $n$th pass (in this case, the first pass) through the iterative loop that has occurred during the present month $i$ in the simulation, equation 6 is solved for $S_{i}{ }^{1}$ with consideration for the $Q_{P A S T_{i}}$ terms in the equation for $Q_{G W_{i}}$ (eq. 10) but not the value of $Q_{P R E S E N T_{i}}$ because it has yet to be determined. Through the storage-stage relation, the calculation of $S_{i}{ }^{1}$ is converted to a corresponding reservoir stage $h_{i}{ }^{1}$. The value of $h_{i}{ }^{1}$ is then used to compute an initial estimate of $C_{i}{ }^{1}$ (fig. 5). Using the estimate of $C_{i}{ }^{1}$, an estimate of $Q_{P R E S E N T_{i}}{ }^{1}$ is obtained and used to re-solve the water-balance equation (eq. 6). Re-solving equation 6 will result in a new estimate of reservoir storage, $S_{i}{ }^{2}$, which will result in new estimates of $h_{i}{ }^{2}$, $C_{i}{ }^{2}$, and $Q_{G W_{i}}{ }^{2}$. The iterative process repeats until the previous estimate of the stage change, $C_{i}{ }^{\mathrm{n}-1}$, agrees with the new estimate of the stage change, $C_{i}{ }^{\text {n}}$, within a specified closurecriteria value (fig. 5). The closure criterion on the iterative loop is placed on $C_{i}$ because it is the change in reservoir stage that controls the volume of water that exchanges between the reservoir and aquifer (eq. 10). When the closure criterion is met, the final estimate of $S_{i}$ is evaluated to determine if the usable reservoir capacity has been completely depleted and failure occurred. Then the FYE model steps forward to evaluate the next month.

The closure criterion determines the precision to which consecutive estimates of $C_{i}{ }^{\text {n }}$ agree within the iterative loop of the FYE model. As the iterative loop converges towards a value of $C_{i}$, the closure criterion specifies when the values of $C_{i}{ }^{\text {n }}$ and $C_{i}{ }^{\text {n-1 }}$ are close enough to provide a reasonable estimate of the value of $C_{i}$, and in turn, a reasonable estimate of $Q_{P R E S E N T_{i}}$. As the value of the closure criterion decreases, successive estimates of $C_{i}$ are required to be known to greater precision before the iterative loop will finish; however, as the closure criterion decreases, computational time will increase. The choice of too large a value for the closure criterion could result in large over- or underestimates of $Q_{P R E S E N T_{i}}$ for each month of the simulation, and, in turn, a large over- or underestimate of the firm yield. Alternatively, the choice of too small a value for the closure criterion will result in increased computational time.

To ensure firm-yield estimates are not affected by the choice of the closure-criterion value for the iterative loop, the difference in firm-yield estimates was compared for closure criterion values of $0.1 \mathrm{ft} / \mathrm{d}, 0.01 \mathrm{ft} / \mathrm{d}, 0.001 \mathrm{ft} / \mathrm{d}$, and 0.0001 $\mathrm{ft} / \mathrm{d}$. The firm yield at each closure criterion was computed for reservoirs A through D using the same 2-year period of stresses, reservoir and aquifer geometries, and reservoir and aquifer characteristics as was used to compare results from the numerical and FYE-model simulations (table 1).

As the closure criterion decreased, the estimate of $Q_{P R E S E N T_{i}}$ was known to greater precision; however, as the closure criterion became more restrictive (less than $0.01 \mathrm{ft} / \mathrm{d}$ ), the firm yield did not change within a value of 1,000 gallons (gal), even when the closure-criterion value was decreased further (fig. 9). Differences between firm yield estimates 

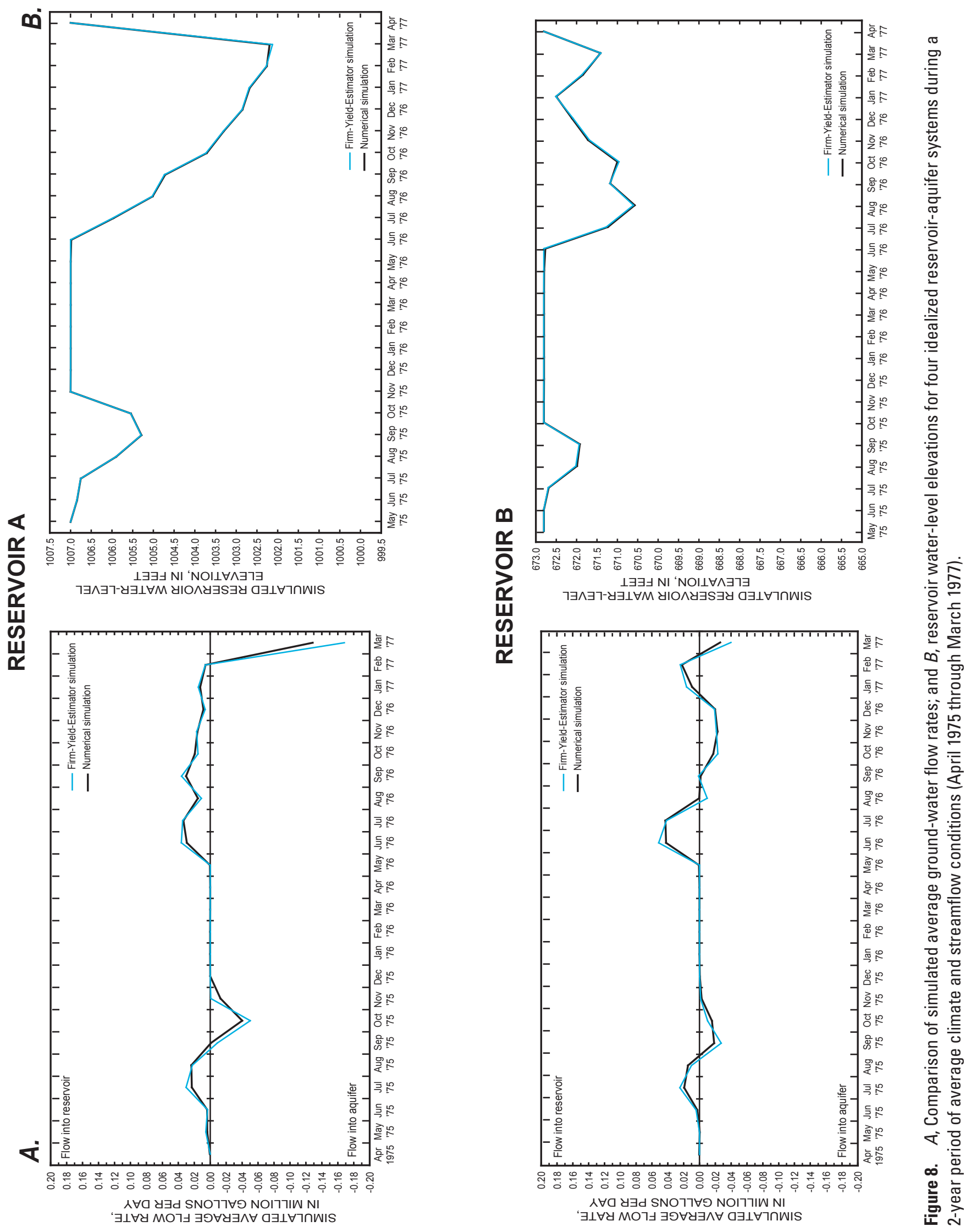

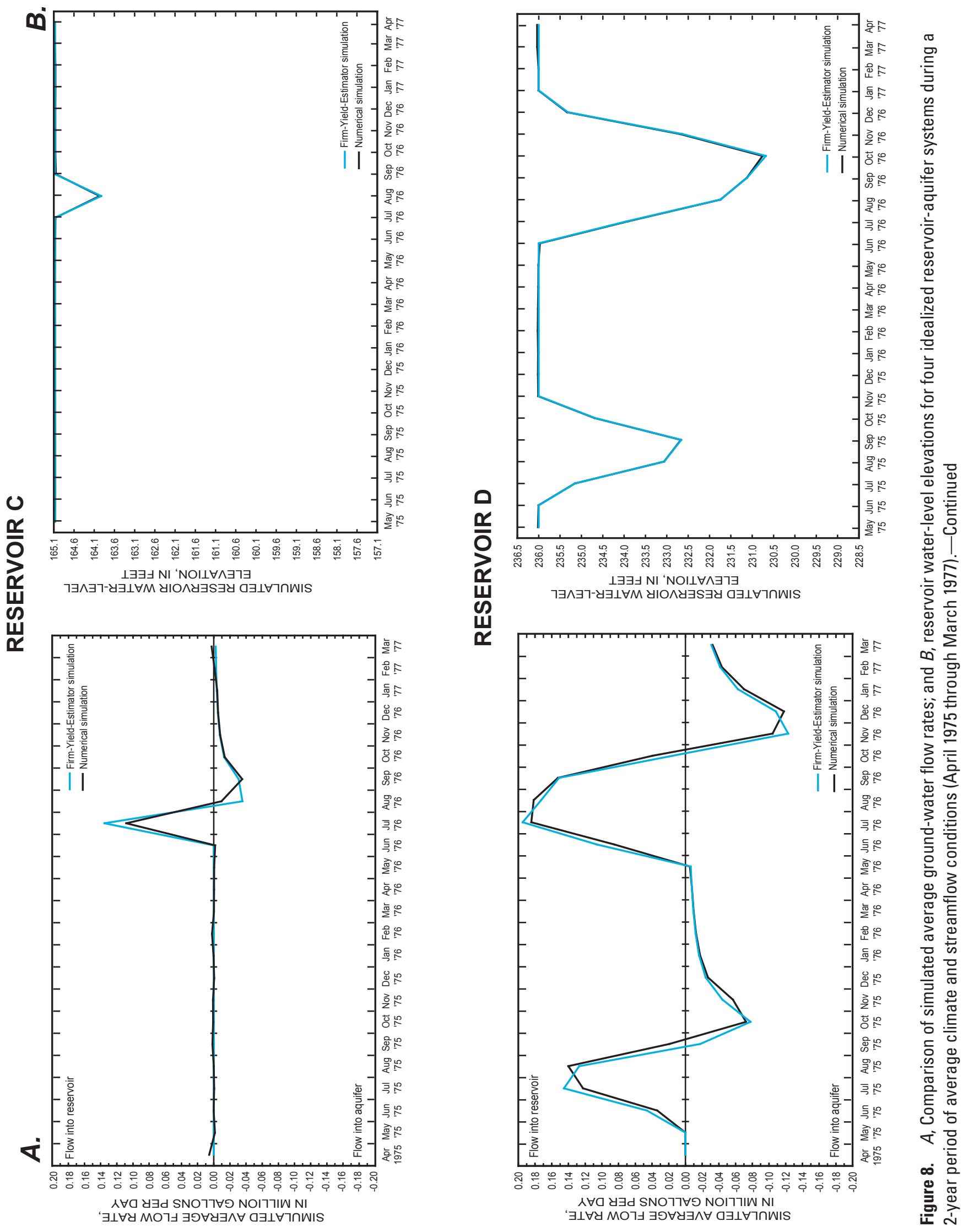


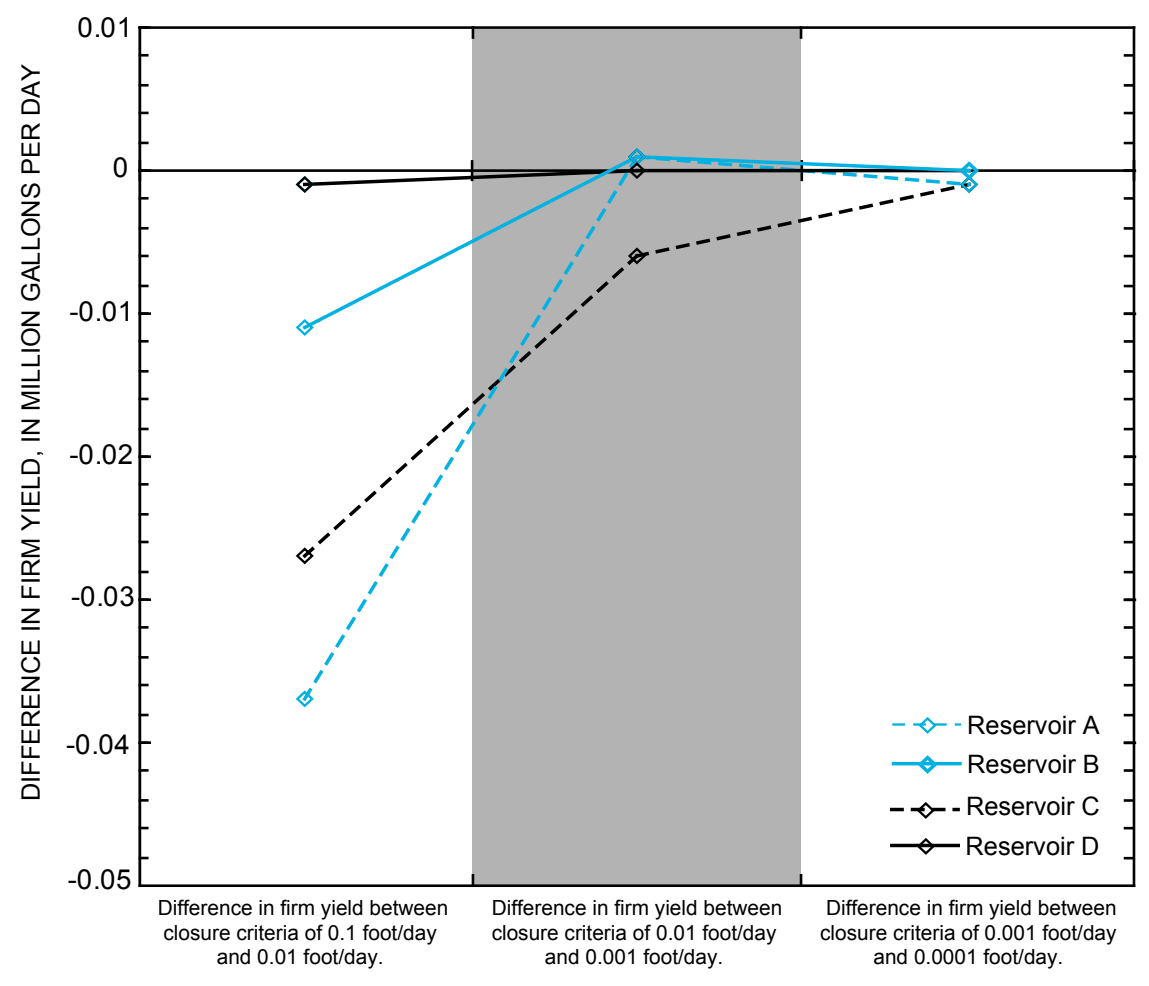

Figure 9. Sensitivity of firm yield to the closure criterion used in the iterative loop of the firm-yield simulations for four idealized reservoir-aquifer systems.

were observed between closure-criteria values of $0.1 \mathrm{ft} / \mathrm{d}$ and $0.01 \mathrm{ft} / \mathrm{d}$ as well as between closure-criteria values of 0.01 $\mathrm{ft} / \mathrm{d}$ and $0.001 \mathrm{ft} / \mathrm{d}$; however, the difference between the firm yield determined from closure-criteria values of $0.001 \mathrm{ft} / \mathrm{d}$ and $0.0001 \mathrm{ft} / \mathrm{d}$ were less than $0.001 \mathrm{Mgal} / \mathrm{d}$ for all idealized reservoir-aquifer systems (fig. 9). Therefore, a closure criterion of of $0.001 \mathrm{ft} / \mathrm{d}$ was used in the FYE model.

\section{Effect of Uncertainty in the Input Variables to the Ground-Water-Flow Equations}

Comparisons of ground-water-flow rates and reservoir water levels for idealized reservoir-aquifer systems indicated that the ground-water-flow equations were applied correctly to the modified FYE model. To apply the modified FYE model to real reservoir-aquifer systems in Massachusetts, one will need to estimate the input variables that are required to determine the ground-water contribution. Because the estimates of these input variables are likely to differ from the true values, the sensitivity of firm yield to the user-specified reservoir-aquifer characteristics (stage-storage relation, $a, L, T$, and $S$ ) was evaluated to quantify differences in firm yield.

\section{Sensitivity of Firm Yield to the Reservoir Stage- Storage Relation}

Although the stage-storage relation for reservoirs A through D was simulated assuming a rectangular-shaped reservoir, the actual shape of a reservoir and the corresponding stage-storage relation is complex. Before the firm yield of a reservoir can be calculated, detailed bathymetric data are used to determine the stage-storage relation for the usable capacities of the reservoirs. For reservoirs A through D, a parsimonious, monotonically increasing polynomial was fit to the bathymetric data collected by Waldron and Archfield (2006) to provide a continuous relation between reservoir storage and stage. Using this relation, the firm yield was then calculated from the 2-year simulation period (April 1975 through March 1977) for reservoirs A through D and compared to the firm yield determined from a stage-storage relation that was based on a rectangular-shaped reservoir. 

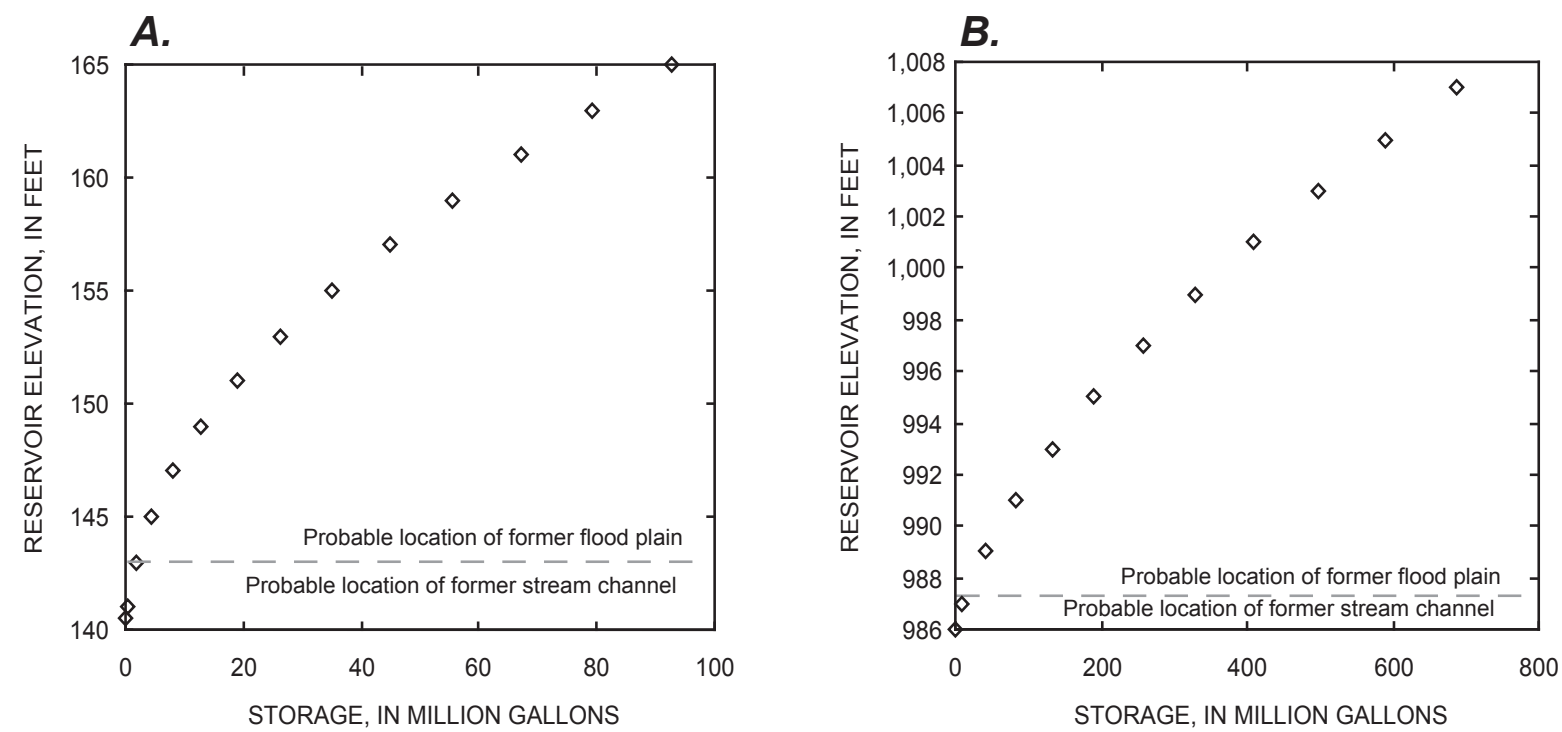

Figure 10. Shape of the stage-storage relation for two drinking-water reservoirs in Massachusetts. As the reservoir drains, the slope increases sharply at the deepest part of the reservoir where the former stream channel is likely located. Two reservoirs are shown: $A$, Bearhole Reservoir, and $B$, Fitchburg Reservoir.

During simulations of reservoirs $\mathrm{C}$ and $\mathrm{D}$, the iterative loop did not converge when water levels approached the bottom of the reservoir. Near the bottom of the reservoir, large changes in reservoir stage induced an unrealistic ground-water flux that overwhelmed the values of the other terms in the water balance (fig. 10). This large overestimate in the groundwater flux prevented the iterative loop from converging or, in some cases, caused the iterative loop to converge at an unacceptably slow rate. Large changes in stage near the bottom of the reservoir are typical of reservoirs in Massachusetts because most drinking-water reservoirs were constructed on an existing stream. Therefore, the deepest part of the reservoir bottom has steeply sloping sides where the stream channel was located, and the upper part of the reservoir bottom is flat with gently sloping sides, representing the location of the former flood plain (fig. 10). Reservoir C was particularly sensitive to this numerical instability not only because of its steeply sloping stage-storage relation but also because the reservoir is in contact with a large aquifer, which resulted in large flow rates between the reservoir and aquifer even for small changes in reservoir storage. It should be noted that, because this numerical instability is caused by the strong curvature in the stagestorage relation (fig. 10), the instability is not apparent when the relation is linear, that is, when the reservoir has a rectangular shape.

Additional changes were made to the modified FYE model to resolve the numerical instability, and these modifications resulted in firm yields for reservoirs $\mathrm{C}$ and $\mathrm{D}$. To test that these modifications did not affect the firm yield, the FYE model was rerun for reservoirs A and B; there was no difference between the firm yields calculated before and after the additional changes. Another resolution to the numerical instability would be for the user to fit a lower-order polynomial that does not account for the steep stage-storage relation near the bottom of the reservoir; however, it should be noted that the firm yield is sensitive to adjustments made in the stage-storage relation. To demonstrate this sensitivity, a comparison was made between the firm yield determined when the reservoir shape was represented as an ideal, straightsided reservoir square and the firm yield determined when the detailed bathymetric data were used to fit a stage-storage relation. This comparison showed that the firm yield was always greater when the more simplified reservoir shape was used in the simulation, with a maximum difference in firm yield of approximately 4 percent.

\section{Sensitivity of Firm Yield to Other Reservoir and Aquifer Input Variables}

The sensitivity of firm yield to the reservoir and aquifer variables $a, L, T$, and $S$ was quantified for reservoirs A through D (fig. 6), which represent a range of typical reservoir-aquifer systems, to understand the variability in firm yield that can be expected if estimates of the reservoir and aquifer characteristics contain uncertainty. For example, values of $T$ and $S$ may be difficult to estimate if detailed aquifer tests and well-bore 

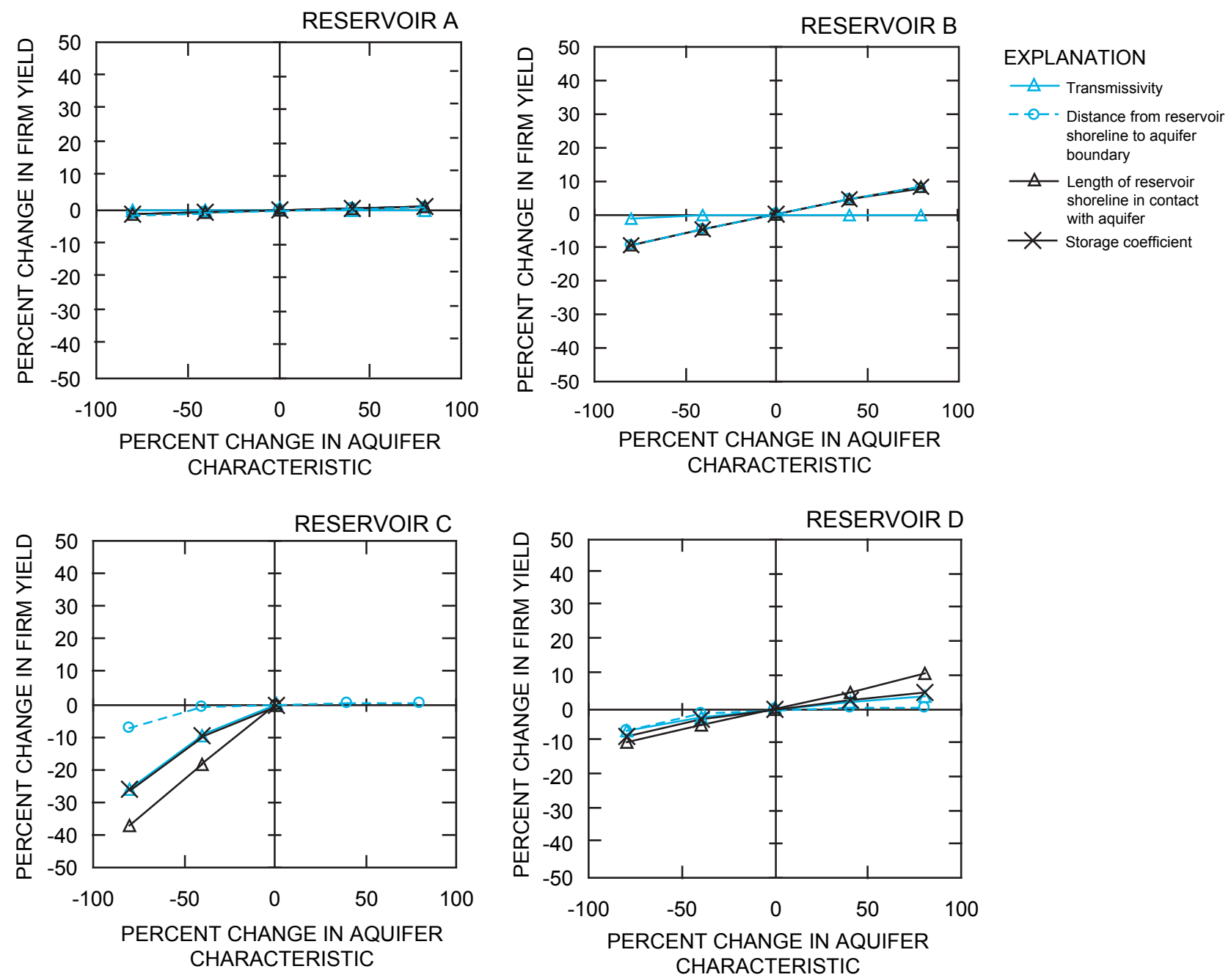

Figure 11. Sensitivity of firm yield to reservoir and aquifer characteristics for four idealized reservoir-aquifer systems. 
information are not available for the reservoir-aquifer system of interest. A sensitivity analysis can provide some information about how the firm yield is affected by these reservoir and aquifer characteristics.

For each study reservoir, the firm yield was determined from the entire historical record of inflows to and outflows from the reservoir by increasing and decreasing the values of $a, L, T$, and $S$ (shown in table 1 ) by 40 and 80 percent for the simulation period. The percent change in firm yield was compared to the percent change in each reservoir-aquifer characteristic (fig. 11). For reservoirs in contact with a relatively small aquifer area (reservoir A and B), the firm yield is equally sensitive to changes in $a, L$, and $S$; however, this sensitivity does not change the firm yield by more than \pm 10 percent (fig. 11). For reservoirs in contact with a relatively large aquifer area (reservoirs $C$ and $D)$, the firm yield is sensitive to changes in $L, S$, and $T$ but not to changes in $a$ (fig. 11). The firm yield is most sensitive to changes in $L$, and the sensitivities of firm yield to changes in $S$ and $T$ are approximately equivalent. Reservoir $\mathrm{C}$ encountered numerical instability when $S, L$, and $T$ were increased beyond their initial values; therefore, the change in firm yield due to increases in $S, L$, and $T$ could not be determined (fig. 11).

\section{Potential Effect of Ground-Water Contributions on Firm Yields for Reservoirs in Massachusetts}

The modified FYE model assumes that both surface water and ground water contribute to reservoir storage. Therefore, if a reservoir has a clearly defined drainage area with some amount of surface-water inflow, the modified FYE model can be applied to reservoir-aquifer systems in Massachusetts; however, it is important to consider the applicability of the modified FYE model to a particular reservoir-aquifer system. For the case in which a reservoir is in contact with a large aquifer and the reservoir has a steep stage-storage relation, the modified FYE model may not result in a firm yield due to numerical instability. Furthermore, because it is not possible to measure actual ground-water-flow rates to compare with the ground-water-flow rates simulated by the modified FYE model, the results of the FYE model have not been validated by observed reservoir conditions. Despite these limitations, the modified FYE model offers a method to determine the firm yield of a reservoir whose shoreline is in contact with an aquifer in the absence of a more detailed, time-consuming, and expensive, two- or three-dimensional numerical ground-water-flow model.
To determine the potential effects of ground-water contributions on firm yields, the firm yields of nine study reservoirs (fig. 12) that have reservoir shorelines in contact with sand and gravel (Waldron and Archfield, 2006) were determined with and without the ground-water contributions. The reservoir and aquifer characteristics (table 2) and reservoir stage-storage relation were estimated for these nine reservoirs and the firm yields were then determined with and without consideration for the ground-water contribution to reservoir storage.

The firm yields were determined by using the entire historical record to solve the monthly water balance. Input variables needed to determine the ground-water contribution were estimated for each reservoir (table 2) in the following ways: $L$ was estimated from GIS digital data layers of hydrography in Massachusetts at a 1:100,000 scale (Office of Geographic and Environmental Information (MassGIS), 2004b); $a$ was estimated from GIS digital data layers of surficial geology in Massachusetts at a 1:250,000 scale (Office of Geographic and Environmental Information (MassGIS), 2004a) and represents an average distance from the reservoir shoreline to the aquifer boundary; $T$ was estimated from hydrologic atlases or previous studies where a ground-water-flow model was developed (see table 2 for references); a value of 0.2 was used for $S$; and the stage-storage relation was determined from the detailed bathymetric data from Waldron and Archfield (2006).

The often-used assumption in firm-yield estimations of negligible ground-water contributions for reservoirs in contact with aquifer sediments was discovered to be not a valid assumption for the reservoirs studied in Massachusetts. The firm yields for the study reservoirs consistently increased when the contribution of ground water determined by time-varying changes in reservoir stage was included in the reservoir water balance, with increases in firm yield ranging from 2 percent to 113 percent and a median increase in firm yield of 10 percent (table 3 ). Two reservoirs had an increase in firm yield greater than 85 percent. Therefore, potential changes in the firm yield due to the contribution of ground-water to reservoir storage are substantial; however, the amount by which the firm yield of reservoir increased was not found to be directly related to any one or combination of reservoir and aquifer characteristics. There may be cases for which the ground-water contribution to a reservoir whose shoreline is in contact with a sand and gravel aquifer is negligible; however, the firm yields of the study reservoirs were always affected by the inclusion of the ground-water contribution in the reservoir water balance (table 3). Therefore, without further study, it is not possible to establish a criterion as to when the ground-water contribution could be considered negligible for some reservoirs. 


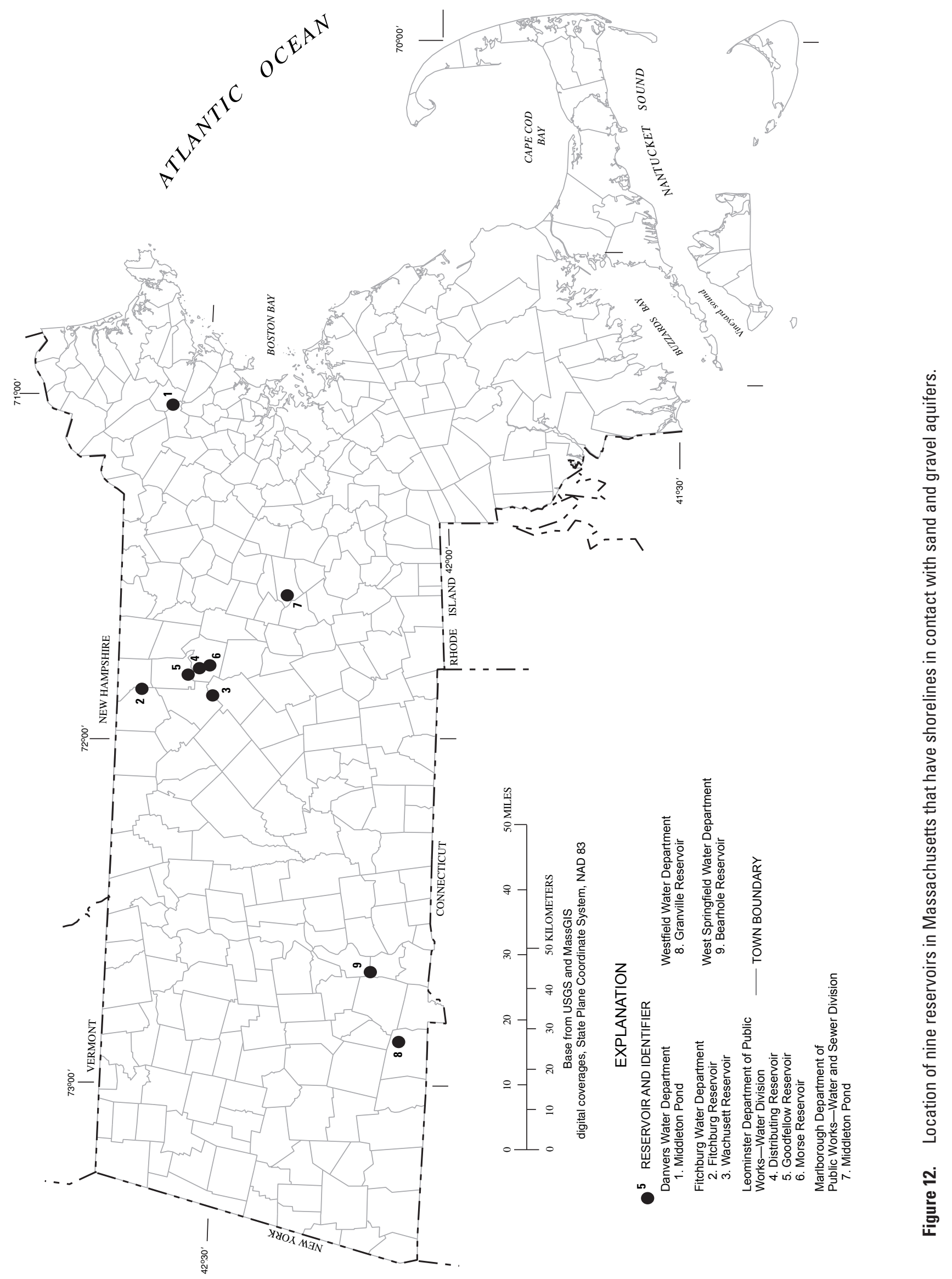



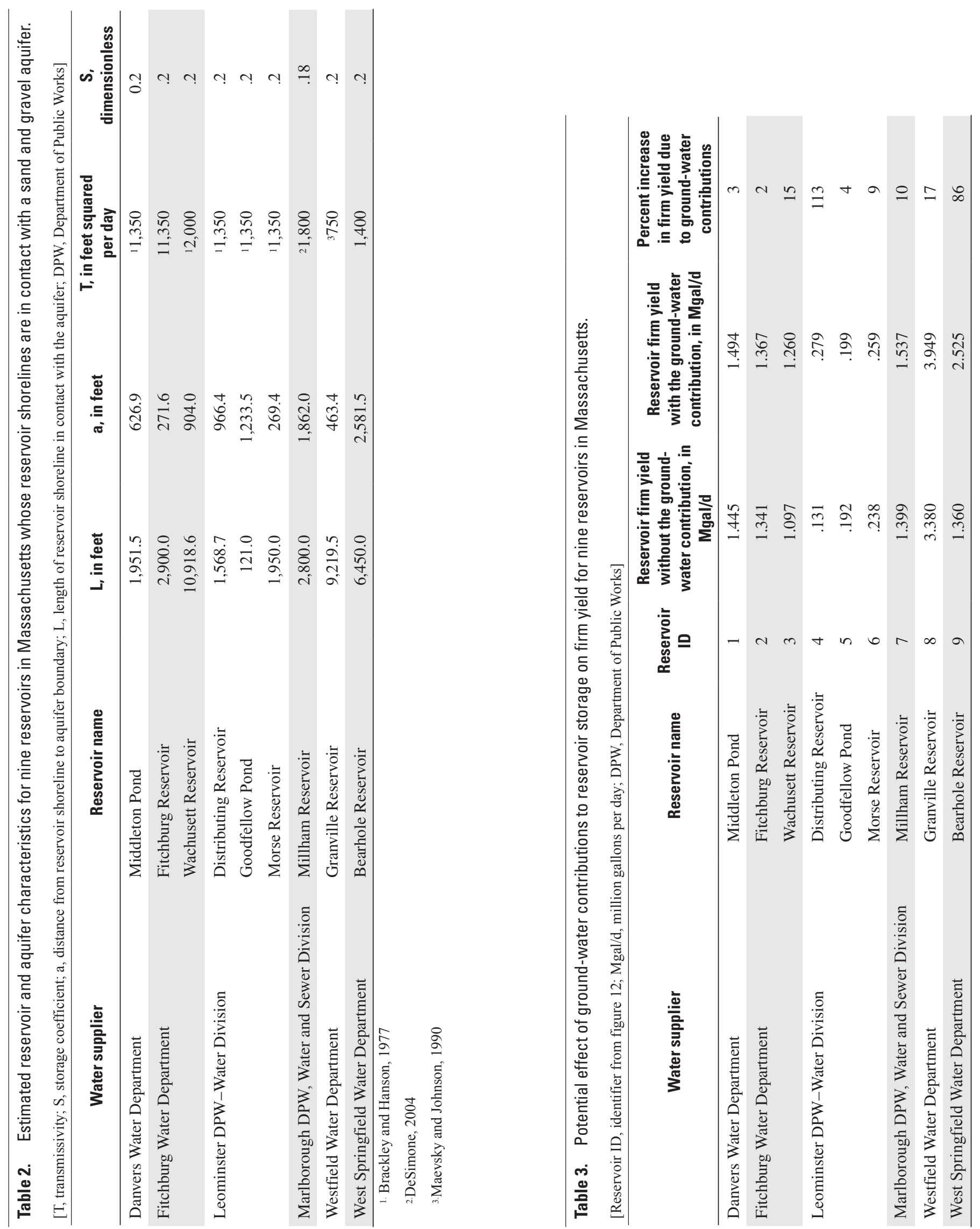


\section{Summary}

The amount of water that is available for withdrawal from a drinking-water supply reservoir depends on the water balance of the reservoir. Because many reservoirs receive most of their water from a surface-water source, the groundwater-inflow term in the water balance is commonly assumed to be negligible and is ignored in the calculation of the firm yield - the maximum yield that can be continually withdrawn from the reservoir. For a reservoir whose shoreline is in contact with an aquifer, however, as is the case for approximately one-quarter of the reservoirs in Massachusetts, the effect of ground-water contributions on firm yield can be substantial, but is unknown because available models that determine firm yield were constructed without consideration for the groundwater contribution to reservoir storage.

To evaluate the potential effect of ground water on firm yield, the U.S. Geological Survey, in cooperation with the Massachusetts Department of Environmental Protection, identified a set of equations that are based on an analytical solution to the ground-water-flow equation for the case of one-dimensional ground-water flow in a finite-width aquifer bounded by a linear surface-water feature such as a stream. These equations, which require only five input variables, were incorporated into the existing firm-yield-estimator (FYE) model, and the potential effect of ground water on firm yield was evaluated.

To apply the FYE model to a reservoir-aquifer system in Massachusetts, the model requires that reservoir drainage areas be clearly defined and that some surface water flows into the reservoir. To determine the ground-water contribution to reservoir storage, the modified FYE model also requires the estimation of the reservoir storage-reservoir stage relation, the transmissivity $(T)$ and storage coefficient $(S)$ of the aquifer, an estimate of the length of reservoir shoreline that is in contact with the aquifer $(L)$, and an estimate of the distance between the reservoir shoreline to the aquifer boundary $(a)$. For surface-water-body shapes having a more realistic representation of a reservoir shoreline than a stream, a comparison of groundwater-flow rates simulated by the ground-water equations and ground-water-flow rates simulated by a two-dimensional, finite-difference ground-water-flow model indicate that the agreement between the simulated flow rates is within \pm 10 percent when the ratio of the distance from the reservoir shoreline to the aquifer boundary to the length of shoreline in contact with the aquifer is between values of 0.5 and 3.5.

The characteristic shape of the storage-stage relation for reservoirs in Massachusetts created numerical instability for some reservoirs when the water level in the reservoir approached the reservoir bottom. Steep slopes in the reservoir stage-storage relation resulted in ground-water-flow rates that were unrealistically high and prevented the calculation of firm yield. Reservoirs in contact with a large aquifer area are particularly susceptible to this problem. Fitting a monotonically increasing, parsimonious function to represent the reservoir stage-storage relation will minimize the possibly of numerical instability. Furthermore, differences in firm yield that result from oversimplification of the storage-stage relation are within 5 percent.

For reservoirs in contact with a small aquifer area, the firm yield is equally sensitive to changes in $a, L$, and $S$; however, this sensitivity does not change the firm yield by more than \pm 10 percent. Therefore, uncertainty in the estimates of input variables $a, L, T$, and $S$ for relatively small aquifer areas are unlikely to substantially affect the resulting firm-yield estimates. For reservoirs in contact with a large aquifer area, the firm yield is sensitive to changes in $L, S$, and $T$ but not to changes in $a$. The firm yield is most sensitive to changes in $L$, and the sensitivities of firm yield to changes in $S$ and $T$ are approximately equivalent.

The effect of ground-water contributions on firm yield was not only substantial, but furthermore, the firm yield of a reservoir in contact with a sand and gravel aquifer was always greater when the ground-water contribution to reservoir storage was included in the water balance. Increases in firm yield ranged from 2 to 113 percent, with a median increase in firm yield of 10 percent. Two reservoirs had an increase in firm yield that was greater than 85 percent.

Idealized reservoir-aquifer systems also were assumed to verify that the ground-water-flow equations were implemented correctly into the existing FYE model; however, the modified FYE model has not been validated through a comparison of simulated and observed data. A comparison of simulated and observed reservoir data would further define limitations to the applicability of the ground-water-flow equations to reservoirs in Massachusetts whose shorelines are in contact with a sand and gravel aquifer.

\section{Acknowledgments}

The authors thank Paul Blain and the Massachusetts Department of Environmental Protection for their support of this project; USGS colleagues Stephen Garabedian, Paul Barlow, Marcus Waldron, and Forest Lyford for their invaluable technical assistance; and Philip Harte and John Masterson of the USGS and Thomas Lamonte of the Massachusetts Department of Environmental Protection for their report reviews. 


\section{References Cited}

Barlow, P.M., and Moench, A.F., 1998, Analytical solutions and computer programs for hydraulic interaction of streamaquifer systems: U.S. Geological Survey Open-File Report 98-415A, 85 p.

Brackley, R.A., and Hansen, B.P., 1977, Water resources of the Nashua and Souhegan River Basins, Massachusetts: U.S. Geological Survey Hydrologic Investigations Atlas HA-276, 2 sheets.

DeSimone, L.A., 2004, Simulation of ground-water flow and evaluation of water-management alternatives in the Assabet River Basin, eastern Massachusetts: U.S. Geological Survey Scientific Investigations Report 2004-5114, 133 p.

Fennessey, N.M., 1994, A hydro-climatological model of daily streamflow for the northeast United States: Medford, Mass., Tufts University, Ph.D. dissertation, variously paged.

Fennessey, N.M., and Vogel, R.M., 1996, Regional models of potential evaporation and reference evapotranspiration for the Northeast USA: Journal of Hydrology, v. 184, p. 337354.

Fetter, C.W., 1994, Applied hydrogeology (3d ed.): Upper Saddle River, N.J., Prentice-Hall, 691 p.

Harbaugh, A.W., Banta, E.R., Hill, M.C., and McDonald, M.G., 2000, MODFLOW-2000, the U.S. Geological Survey modular ground-water model-User guide to modularization concepts and the ground-water flow process: U.S. Geological Survey Open-File Report 00-92, 121 p.

Maevsky, Anthony, and Johnson, D.G., 1990, Water resources of the Westfield and Farmington River Basins, Massachusetts: U.S. Geological Survey Hydrologic Investigations Atlas HA-716, 4 sheets.
Massachusetts Department of Environmental Protection, 1996, Estimating the firm yield of a surface water reservoir supply system in Massachusetts-A guidance document, Version 1.0: Massachusetts Department of Environmental Protection, Office of Watershed Management, variously paged.

Office of Geographic and Environmental Information (MassGIS), Version 1.0, Software documentation: Prepared by Cambridge Environmental Inc. for the Massachusetts Department of Environmental Protection, Office of Watershed Management, variously paged.

Natural Resources Conservation Service, 1986, Urban hydrology for small watersheds: Natural Resources Conservation Service, Conservation Engineering Division, Technical Release 55, 164 p. (http://www.hydrocad.net/tr-55.htm)

Office of Geographic and Environmental Information (MassGIS), 2004a, Commonwealth of Massachusetts Executive Office of Environmental Affairs, 1:250,000-scale surficial geology digital data layer for sand and gravel deposits in Massachusetts; accessed on July 5, 2005, at http://www. mass.gov/mgis/ftpsg.htm

Massachusetts Department of Environmental Protection, 2004b, Commonwealth of Massachusetts Executive Office of Environmental Affairs, 1:100,000-scale hydrography digital data layer for surface-water bodies in Massachusetts; accessed on July 5, 2005, at http://www.mass.gov/mgis/ ftphd100_.htm

Rorabaugh, M.I., 1964, Estimating changes in bank storage and ground-water contribution to streamflow: International Association of Scientific Hydrology, Publication 63, p. 432441. 
For additional information write to:

Director,

USGS Massachusetts-Rhode Island Water Science Center 10 Bearfoot Road

Northborough, MA 01532

or visit our Web site at

http://ma.water.usgs.gov 